ONDERZOEKSRAPPORT NR 9307

The Persistence of Marketing Effects on Sales

by

Marnik G. DEKIMPE

Dominique M. HANSSENS

D/1993/2376/7 


\title{
THE PERSISTENCE OF MARKETING EFFECTS ON SALES
}

\author{
Marnik G. Dekimpe
}

Catholic University Leuven

and

Dominique M. Hanssens ${ }^{2}$

University of California, Los Angeles

March 1993

1. Assistant Professor, Department of Applied Economic Sciences, Catholic University Leuven, de Beriotstraat 34, 3000 Leuven, Belgium (E-mail: FDBAA04@BLEKUL11; Tel. (32-16) 284-549).

2. Professor, The Anderson Graduate School of Management, University of California, Los Angeles, 405 Hilgard Avenue, Los Angeles, CA 90024-1481 (E-mail: DHANSSEN@AGSM.UCLA.EDU; Tel. (310) 825-4497).

The authors are grateful to Donald G. Morrison for helpful comments on an earlier draft. 


\title{
THE PERSISTENCE OF MARKETING EFFECTS ON SALES
}

\begin{abstract}
Are marketing efforts able to affect long-term trends in sales or other performance measures? Answering this question is essential for the creation of marketing strategies that deliver a sustainable competitive advantage. This paper introduces persistence modeling to derive longterm marketing effectiveness from time-series observations on sales and marketing expenditures. First, we use unit-root tests to determine whether sales are stable or evolving (trending) over time. If they are evolving, we examine how strong this evolution is (univariate persistence) and to what extent it can be related to marketing activity (multivariate persistence). An empirical example on sales and media spending for a chain of home-improvement stores reveals that some, but not all, advertising has strong trend-setting effects on sales. We argue that traditional modeling approaches would not pick up these effects, and therefore seriously underestimate the long-term effectiveness of advertising. The paper concludes with an agenda for future empirical research on long-run marketing effectiveness.
\end{abstract}




\section{INTRODUCTION}

In a recent article on declining sports-car sales in the United States, The Economist writes "... Many dealers worry that the drop in sports-car sales is not just the result of recession, but could herald a permanent decline in their popularity." (The Economist, August 29,1992, p. 63). The article goes on to describe pricing and advertising strategies employed by Chevrolet Corvette and its competitors in an attempt to revive product sales. It illustrates an often recurring and important dual question for marketing executives and researchers: are observed upturns or downturns in sales of a temporary or permanent nature, and, in the latter case, how do marketing strategies affect such long-run sales movements?

Answering these questions is essential for the development of marketing strategies that deliver a sustainable competitive advantage for the brand or company. Yet, our understanding of long-run marketing phenomena is far from complete. In a literature that has traditionally devoted more attention to the short-term impact of marketing strategies than to their potential long-run implications, three approaches to study long-run marketing phenomena have emerged: the dynamic effects of marketing expenditures have been measured with distributed-lag and/or transfer-function models (Hanssens, Parsons and Schultz 1990), the persistence of first-mover advantages has been assessed through cross-sectional designs (Urban, Carter, Gaskin and Mucha 1986), and concepts such as brand loyalty, brand equity and brand franchise (Simon and Sullivan 1993) attempt to develop a distinct metric to capture a brand's long-run performance.

We argue in this paper that the shortcomings of these approaches necessitate a new approach which we call persistence modeling. Marketing is defined to have a persistent (or permanent) effect on a brand's performance if a portion of its observed short-run impact is 
carried forward and sets a new trend in performance. On the other hand, marketing has a temporary effect if, after a number of periods, the brand returns to its pre-expenditure performance level. In order to establish persistence, two questions must be answered. First, we must determine if sales are stable or evolving. Stable sales fluctuate temporarily around a fixed mean, while evolving sales have no fixed mean and can deviate permanently from previous levels. We will describe methods for establishing stability or evolution empirically. Second, if we find sales evolution, we examine whether or not it can be traced to marketing efforts. For that, we perform persistence calculations to determine what fraction of the shortterm marketing effects is carried forward and affects the long-run performance.

Persistence modeling introduces a new way of looking at the over-time effectiveness of marketing activities, and differs in two important ways from traditional market-response models. First, rather than focusing on the individual carry-over or purchase-reinforcement coefficients, we derive the total long-run impact of a marketing action in that an initial outlay receives credit for all subsequent effects that follow from it. We argue that several channels of influence should be taken into account when computing the total long-run impact of a marketing activity: instantaneous, carry-over, purchase-reinforcement and feedback effects, as well as the effects resulting from firm-specific decision rules or competitive reactions. Second, rather than looking at the absolute price or marketing spending levels, we consider the differential impact of temporary deviations from the brand's expected marketing support. Indeed, recent individual-choice models suggest that consumers form expectations about future marketing activities of a brand from their past exposure to such activity, and argue that consumer response is influenced by the disparity between the resulting reference point and the 
actual level of marketing support (see e.g. Lattin and Bucklin 1989). A similar philosophy is adopted in our approach, though we consider expectations and disparities at the aggregate rather than at the individual level.

We use persistence modeling to compare the short- and long-run effectiveness of different advertising media used by a large home-improvement chain, and illustrate how some of our findings could not have been obtained with traditional approaches. Our results will show that temporary advertising increases or shocks can have a permanent effect on a brand's performance, which is empirical evidence for the hysteresis effect described by Little (1979). To the best of our knowledge, our study is the first to quantify hysteresis using ETS (econometric and time-series) models. Our analysis also illustrates that long-run marketing impact emerges from a complex dynamic interaction of a variety of short-term forces. Finally, our example demonstrates that different media can have different long-run effects.

The remainder of the paper is organized as follows. In Section 2, we briefly review some approaches that are currently used to study long-run marketing phenomena. Section 3 introduces the persistence concept, both in a univariate and multivariate context. The empirical application is discussed in Section 4. Section 5 summarizes our main findings and indicates some areas for future research.

\section{CRITERIA AND METHODS FOR LONG-RUN MODELING}

We begin by positing that a meaningful measure of long-run marketing effectiveness should satisfy the following criteria:

- it should quantify the long-run performance impact of specific marketing 
actions,

- it should recognize that, as market conditions change, the over-time effectiveness of marketing actions may be different,

- it should recognize that long-run sales (market-share, ...) performance emerges out of a sequence of short-run sales (market-share, ...) movements.

The quantification of long-run marketing effects is essential for developing empirical generalizations in marketing and for designing fact-based marketing strategies aimed at the creation of sustainable competitive advantage. Second, all products move through life cycles which are characterized by successive periods of evolution (e.g. growth and decline) and stability (e.g. maturity). Marketing investments often serve different purposes during the life cycle, for example awareness building followed by product differentiation, and we can expect their effectiveness to be different in evolutionary versus stable times. Models aimed at quantifying the long-run impact of marketing activities should be able to detect these differences if they exist. Finally, we argue that while long-run sales or profit performance should be the ultimate goal of management, only short-run performance is readily observed. Therefore, long-run market-response models should provide a necessary link between the two.

To put our modeling framework in perspective, we assess to what extent currently used approaches to long-run modeling satisfy these criteria.

\subsection{The Over-time Distribution of Marketing Effects}

Recognizing that marketing expenditures often do not have their full impact in the 
period in which they are incurred, market-response models make extensive use of distributedlag structures. A typical approach is to assume that a fixed fraction $(\lambda)$ of the marketing effects in one period $\left(b_{\mathrm{i}}\right)$ will be retained in the next period, i.e. $b_{\mathrm{i}+1}=\lambda b_{i}$, where $0 \leq \lambda<$ 1. Clarke (1976) used this geometrically decaying pattern to conclude that $90 \%$ of the measurable effects of advertising on a mature product's sales will be consumed within three to nine months. ${ }^{1}$ While his conclusion is interesting, it does not address the more fundamental question whether marketing expenditures can have a persistent or permanent effect. The Koyck specification implies that sales eventually return to their pre-expenditure level, since $\lim _{0 \rightarrow \infty} \lambda^{n}=0$, for $0 \leq \lambda<1$. Hence, persistent effects can never be found, and the brand's steady-state or equilibrium sales are given by a constant from which marketing expenditures can cause temporary deviations.

The behavior implied by distributed-lag models does not conform with the more complex longitudinal sales patterns one often observes, such as the presence of prolonged upor downward trends. Such trends are typically modeled by including deterministic time factors in the response equation. Adding a deterministic trend, however, implies that sales will steadily rise or decline, regardless of the level of marketing support. Not only may this result in implausible forecasts, these models also have little appeal in terms of management's control over the evolution of its brands.

In sum, traditional response models are appropriate for measuring long-term marketing effects in fairly stable environments: they quantify the over-time impact of marketing activities, and allow to distinguish between instantaneous and lagged effects. In evolving environments, however, these models do not determine whether the firm's marketing efforts 
are affecting the long-run performance evolution of a brand. Therefore, traditional marketresponse models may seriously underestimate the power of marketing in the long run.

\subsection{Measuring Long-run Equilibria Using Cross-sectional Designs}

Cross-sectional designs have been used to assess long-run equilibrium relationships. ${ }^{2}$ In this framework, the long run is represented by the static solution (i.e. $x_{\mathrm{t}}=x_{\mathrm{t}-\mathrm{i}}, i=1,2, \ldots$ ) that is supposed to arise "after the dust has settled," and all short-term adjustments have taken place (Spanos 1986). An advantage of this cross-sectional design is the large sample size that is easily obtained. On the other hand, the estimated coefficients are likely to be affected by heterogeneity bias, and may not reflect the actual long-run relationship for one brand or industry. Lambkin and Day (1989) therefore argue that more insights can be obtained by sacrificing this large sample size in favor of a longitudinal analysis of a single brand or industry. Also, the estimation of the long-run equilibrium of interest requires the specification of a simultaneous-equation model, but it is often difficult to posit the correct structural model from prior knowledge alone. Finally, the static nature of cross-sectional designs precludes the consideration of events that occur over time. As such, one cannot infer how the short-term dynamics (estimated with longitudinal data) translate into a long-run equilibrium.

In conclusion, while cross-sectional designs quantify long-run equilibria, the static nature of the data makes the approach not well suited to study dynamic behavior. 


\subsection{The Use of a Distinct Long-run Metric}

Recently, new metrics have been designed to measure the long-run impact of marketing investments. Blattberg and Neslin (1989) assess the short-term effects of sales promotions on the brand's sales or profitability, but advocate measuring possible long-run effects through changes in consumer franchise. Simon and Sullivan (1993) argue that brand equity should be used to evaluate the long-run impact of marketing decisions. Studies on the effect of marketing expenditures on brand image (Louviere and Johnson 1988) or brand loyalty (Johnson 1984) are other attempts to adopt a different performance measure when studying longer-run phenomena.

In terms of our criteria for long-run measurement, these new metrics are rather limited. First, they cannot be used to measure the long-run performance impact of a firm's marketing decisions. Simon and Sullivan (1993) perform an event study to assess the impact of some major (discrete) marketing events on a financial-market based equity measure. Consequently, their method cannot be used to assess the impact of a gradual increase in marketing support. Second, it is not clear what will happen after the event window: will the brand equity return to its pre-event value, or will it settle at a new and higher level? While brand equity is supposed to be a long-run measure, one cannot use this operationalization to assess whether a specific event such as a new advertising campaign has a temporary (meanreverting) or permanent (mean-changing or trend-setting) effect. A similar comment applies to Kamakura and Russell's (1991) brand-equity measure. They adopt a random-utility framework in which the utility of a brand is decomposed into two elements: a component of intrinsic (i.e. long-run) value and a component which can be explained by environmental 
factors such as price and short-term advertising exposure. Long-term advertising effects are assumed to be "implicitly incorporated" (p.6) in the brand-specific intercept of the associated logistic regression. Therefore, the researcher cannot distinguish long-run advertising effects from the long-run impact of a chosen pricing strategy, since both are reflected in the same intercept term. Also, we don't know if this intercept is stable or changes over time. Third, it is not clear how these long-run metrics relate to short-run sales movements. For example, as the annual sales of Porsche in the U.S. have plummeted from 25,000 to 4,000 in the last three years, does this imply that Porsche's brand equity is eroding?

In conclusion, while brand equity and other metrics are useful constructs, they are difficult to quantify or use in marketing-effectiveness research.

\section{MULTIVARIATE PERSISTENCE:}

\section{A NEW APPROACH TO LONG-RUN MODELING}

Our framework consists of three major steps. First, we assess the presence of evolution versus stability in sales (or market share) by investigating its behavior over time. If a brand's performance fluctuates around a fixed mean level (i.e. stability), no long-run marketing effects can be inferred from the data since performance always returns to its preexpenditure mean level. If sales are not mean-reverting, an evolutionary or long-run component is present, and marketing can (but need not) cause a permanent deviation from previous sales levels. Unit-root tests are introduced in Section 3.1 to empirically distinguish mean-reverting from evolving patterns. The presence of a unit root implies that a portion of a sudden change in performance (a shock) will persist through time, and affect its long-run 
behavior. Univariate persistence measures are used to assess the relative magnitude of this retained portion, and determine how much an estimate of the brand's long-run performance should be updated when its current performance is, say, $10 \%$ higher than expected on the basis of its past history (Section 3.2). Univariate persistence gives a first indication of the relative importance of short- and long-run performance fluctuations, but does not consider the source of the initial shock. So, in updating a brand's long-run sales forecast, no distinction is made between a $10 \%$ sales increase caused by additional advertising support and a $10 \%$ increase due to economic expansion or a temporary price reduction. Multivariate persistence measures make that distinction, as discussed in Section 3.3.

\subsection{Are Sales Performance and Marketing Support Stable or Evolving?}

The important distinction between stability and evolution is formalized through the unit-root concept. Consider for simplicity the case where a brand's sales over $\operatorname{time}^{3}\left(S_{\imath}\right)$ are described by a first-order autoregressive process:

$$
(1-\phi L) S_{t}=c+u_{t}
$$

where $\phi=$ an autoregressive parameter,

$L=$ the lag operator, i.e. $L^{k} S_{\mathrm{q}}=S_{\mathrm{t}-\mathrm{k}}$,

$u_{h}=$ a series of zero-mean, constant-variance $\left(\sigma_{v}^{2}\right)$ and uncorrelated random shocks, $c=$ a constant.

Applying successive backward substitutions allows us to write equation (1) as 


$$
S_{z}=[c /(1-\phi)]+u_{t}+\phi u_{t-1}+\phi^{2} u_{t-2}+\ldots
$$

in which the present value of the variable is explained as the weighted sum of an infinite number of random shocks. Depending on the value of $\phi$, three situations can occur.

First, when $|\phi|<1$, the influence of past shocks diminishes, and becomes negligible after a number of periods. Each shock therefore has only a temporary impact. In this case, the series has a fixed mean $E\left(S_{t}\right)=[c /(1-\phi)]$ and a finite variance $\sigma_{v}^{2} /\left(1-\phi^{2}\right)$. Such a series is said to be stable.

Second, when $|\phi|=1$, equation (2) reduces to a random-walk model:

$$
S_{t}=(c+c+\ldots)+u_{t}+u_{t-1}+\ldots,
$$

implying that each random shock has a permanent effect on the brand's sales. In this case, no fixed mean is observed, and the variance increases with time. Sales do not revert to a historical level, but instead wander freely in one direction or another, i.e. they evolve.

Distinguishing between the first two situations involves checking whether the autoregressive polynomial $(1-\phi L)$ in equation (1) has a root on the unit circle.

Finally, when $|\phi|>1$, past shocks become more and more important, and the series explodes to plus or minus infinity. Situations where the past becomes ever more important are unrealistic in marketing. We therefore focus our attention on the first two cases.

The previous discussion used the first-order autoregressive model to introduce the concepts of stability, evolution and unit roots. The findings can easily be generalized to the more complex autoregressive moving-average process (ARMA(p,q)) 


$$
\left(1-\phi_{1} L-\phi_{2} L^{2}-\ldots-\phi_{p} L^{D}\right) S_{t}=c+\left(1-\theta_{1} L-\ldots-\theta_{q} L^{q}\right) u_{t}
$$

The MA part, given by the polynomial $\left(1-\theta_{1} L-\ldots-\theta_{\mathrm{q}} L^{\mathrm{q}}\right)$, by definition represents temporary movements, since the effect of any shock becomes zero after $q$ periods. The stable or evolving character of a series is therefore determined by whether some of the roots of the autoregressive polynomial $\left(1-\phi_{1} L-\ldots-\phi_{\mathrm{p}} L^{\mathrm{p}}\right)$ are lying on the unit circle. ${ }^{4}$

Numerous statistical tests have been developed to distinguish stable from evolving patterns (see e.g. Diebold and Nerlove 1990). One popular test, due to Dickey and Fuller (1979), is based on the following test equation:"

$$
(1-L) S_{t}=\Delta S_{t}=a_{0}+b S_{t-1}+a_{1} \Delta S_{t-1}+\ldots+a_{m} \Delta S_{t-m}+u_{t}
$$

The $t$-statistic of $b$ is compared with the critical values in Fuller (1976), and the unit-root null hypothesis is rejected if the obtained value is smaller than the critical value. Indeed, substituting $b=0$ in (5) introduces a random-walk component in the model, whereas $-1<b<0$ implies a mean-reverting process. The $m \Delta S_{1-\mathrm{j}}$ terms reflect temporary sales fluctuations, and are added to the test equation to make the residual series $u_{4}$ white noise.

\subsection{Univariate Persistence or "How Important are the Long-run Components?"}

Unit-root tests were introduced to empirically distinguish stable from evolving markets. The current Section focuses on the quantitative importance of the identified evolving (or long-run) components, which will give us a first indication on how effective marketing can be in the long run. Indeed, if long-run sales fluctuations are only of marginal importance, most marketing effects will still be temporary. 
The presence of a unit root implies that a portion of a shock in sales will persist through time and affect its long-run behavior. The magnitude of this portion reflects the relative importance of the long-run component in a brand's over-time behavior, and determines how much an estimate of the brand's long-run sales or market share should be changed when the current performance is lower than expected on the basis of its past history. ${ }^{6}$ In the absence of a unit root, the continuing effect of a shock is zero: sales return to their pre-shock mean level, and the long-run forecast is not affected by a lower-thanexpected current performance. For a pure random-walk process (ARIMA(0,1,0)), the best forecast at any point in time is current sales. Hence, a one-unit sales decrease today translates into a one-unit reduction of the long-run forecast. This is also shown in equation (3), which gave the infinite-shock representation of a random-walk process. It is clear that a unit shock in $(t-k)$ will have a unit impact on all future values of $S_{t}$. In contrast, for an $\operatorname{ARIMA}(0,1,1)$ model with $\theta_{1}=0.6$, equation (3) becomes

$$
S_{t}=S_{t-1}+\left(u_{t}-0.6 u_{t-1}\right)=u_{t}+0.4 u_{t-1}+0.4 u_{t-2}+0.4 u_{t-3}+\ldots
$$

In this case, only $40 \%$ of an initial shock keeps influencing the brand's future sales levels, and an unexpected $\$ 100,000$ sales decrease in the current period would lead to a $\$ 40,000$ reduction in the long-run forecast. For still other values of the autoregressive and/or movingaverage parameters, the magnitude of the retained portion may be even smaller.

Campbell and Mankiw (1987a,b) developed a simple procedure to derive a series' univariate persistence as the sum of the moving-average coefficients of the first-differenced series. Consider the following univariate ARIMA specification 


$$
\Phi(L) \Delta S_{z}=\Theta(L) u_{t}
$$

The infinite-shock representation of $\Delta S_{\mathrm{t}}$ is given by

$$
\Delta S_{t}=[\Phi(L)]^{-1} \Theta(L) u_{t}=A(L) u_{t}=\left(1+a_{1} L+a_{2} L^{2}+\ldots\right) u_{t}
$$

The impact of a unit shock in period $t-k$ on the sales growth in $t$ is $a_{t}$ (i.e. the partial derivative of $\Delta S_{\mathrm{t}}$ with respect to $u_{\mathrm{t}-\mathrm{t}}$ ). Its impact on the sales level in $t$ is $1+a_{1}+\ldots+a_{\mathrm{t}}$, as is easily seen by taking the partial derivative of $S_{\mathrm{t}}$ with respect to $u_{t-t}$ in equation (9)

$$
S_{t}=(1-L)^{-1}\left(u_{t}+a_{1} u_{t-1}+\ldots\right)=\sum_{-\infty} u_{i}+a_{1} \sum_{-\infty}^{-1} u_{i}+\ldots+a_{k} \sum_{-\infty}^{-k} u_{i}+\ldots
$$

Thus, the long-run impact of a unit shock on the level of $S_{\mathrm{t}}$ is given by the sum of the moving-average coefficients in equation (8), and is often denoted as $A(1)$. Equation (8) shows that $A(1)$ can also be estimated by fitting low-order ARMA models to $\Delta S_{t}$, since

$$
A(1)=\Theta(1) / \Phi(1) \text {. }
$$

In summary, univariate persistence estimates can be obtained by fitting low-order ARMA models to $\Delta S_{t}$, and taking the ratio of the sum of the moving-average coefficients $\left(1-\theta_{1}-\ldots\right.$ $\left.-\theta_{q}\right)$ to the sum of the autoregressive coefficients $\left(1-\phi_{1}-\ldots-\phi_{p}\right) .^{7}$

Univariate persistence gives a first indication on the potential for long-run marketing effectiveness by measuring what proportion of any shock will affect sales permanently. It is particularly useful to measure the long-run impact of an isolated event. For example, Pesaran and Samiei (1991) estimated the univariate persistence to assess the impact of a (temporary) rumor about salmonella poisoning on the long-run evolution of egg production in the U.K. In a marketing context, univariate persistence estimates may prove useful to assess 
the long-run impact of negative product news, a short-lived "special" advertising campaign or temporary price deals. Traditionally, these phenomena have been studied with intervention analyses (e.g. Leone 1987). These require the presence of a sufficiently long post-event history, while persistence models are based on the properties of the pre-event history. Persistence models therefore have to assume that the event does not change the process that generates sales, while intervention models investigate (ex post) the need to alter the underlying model. If the necessary data are available, which only happens after a sufficiently long period of time, intervention analysis is a more powerful technique. However, since persistence estimates do not need post-event data, they may be of more practical use to a decision maker.

\subsection{Multivariate Persistence}

Multivariate persistence derives the long-run impact of an unexpected change in a marketing variable. We first discuss in some detail two distinctive features of the multivariate-persistence concept: the quantification of a marketing decision's total impact and the unexpected nature of the considered outlay. Next, we discuss the mechanics involved in the derivation of multivariate persistence estimates.

\section{The total effect}

The marketing literature has identified six channels through which a marketing action can influence a brand's performance: 1) contemporaneous, 2) carry-over, 3) purchasereinforcement, and 4) feedback effects, 5) firm-specific decision rules and 6) competitive 
reactions. In quantifying the total long-run impact of a marketing action, all channels of influence should be accounted for. A similar logic can be found in Bass and Clarke, who state that "credit for the second purchase should be assigned to the expenditure which induced trial" (1972, p. 300). In what follows, we present a brief motivation for considering each of these effects. For expository purposes, we focus on the advertising-sales relationship.

Contemporaneous effects. Consensus exists in the marketing field that advertising often has a considerable immediate impact. Using single-source data, Abraham and Lodish (1991) conclude that about half of all TV-advertising plans have a measurable sales effect in the period of execution, and Leone and Schultz (1980) call the positive elasticity of selective advertising on a brand's sales one of marketing's first empirical generalizations.

Carry-over effects. Numerous studies have argued that the effect of advertising in one period may be "carried over," at least partially, into future periods (see e.g. Givon and Horsky 1990). Consumers are supposed to remember past advertising messages and create "goodwill" towards the brand. However, because of a gradual forgetting, only part of an initial effect remains effective in subsequent periods. Following the work of Palda (1964), a geometric decay has frequently been used to characterize this forgetting effect. As indicated in Section 2.1, this specification imposes a mean-reverting property on sales, and captures only two channels of influence: instantaneous and carry-over effects.

Purchase reinforcement. Givon and Horsky (1990) argue that the dynamic impact of advertising on sales can also work indirectly through purchase reinforcements: a given outlay may create a new customer who will not only make an initial purchase, but also repurchase in future periods. Using a similar logic, Horsky and Simon (1983) assume that advertising 
gives innovators an incentive to try the product after which an imitation effect takes over, creating a larger customer base and higher future sales. According to Bass and Clarke (1972) and Hanssens et al. (1990, p. 49), current advertising outlays should receive credit for these subsequent sales, since, without the effort, no incremental sales would have occurred.

Feedback effects. Bass (1969) warned that advertising spending may be influenced by current and past sales, and should not be treated as exogenous. This is certainly the case when percentage-of-sales budgeting rules are applied. Bass and Parsons (1969) use a simultaneous-equations model to include the effect of past sales on future advertising budgets in their model of the American cigarette industry. Their model allows for contemporaneous, purchase-reinforcement and competitive-reaction effects, and also captures an autoregressive pattern in the firms' advertising spending. Only carry-over effects are not explicitly incorporated. While capturing most channels of influence, they focus on the short-term coefficients rather than on the total long-run impact. To illustrate the importance of feedback effects in the derivation of this total impact, consider the following chain reaction initiated by a one-period advertising increase: increased advertising in period $t \rightarrow$ increased sales in $t \rightarrow$ increased advertising in $t+1 \rightarrow$ increased sales in $t+1 \rightarrow \ldots$ Credit should be given to the initial advertising increase for all subsequent sales increases since without it, none of these effects would have occurred.

Firm-specific decision rules. Traditional single-equation models treat advertising as exogenous, and do not explicitly model the dependence of current on previous expenditure levels. Empirical evidence contradicts this "independence" assumption: most published timeseries models find significant autoregressive components in a firm's spending pattern (see e.g. 
Helmer and Johansson 1977; Hanssens 1980a,b). In other words, spending levels this January tend to be related to last December's and/or last January's advertising. Here again, a chain reaction may occur and help determine advertising's total long-run impact. For example, without an increase in last January's advertising, this January's spending would have been lower and less sales would have resulted. ${ }^{8}$

Similarly, when measuring advertising's long-run impact, one should also allow for coordinated marketing decision making, i.e. the scenario where one marketing instrument affects or is affected by the level of another instrument in the same firm (Hanssens 1980b). In this way, long-run synergy effects of a coordinated marketing strategy may be found.

Competitive reactions. Competitive activities may change advertising's effectiveness drastically. For example, even though the instantaneous sales response to advertising may be positive, its long-run effect could be zero because of competitive reactions. This selfcanceling (and often escalating) effect of competitive expenditures was observed by Metwally (1978) in a number of Australian industries.

Summary. While there is consensus that each of the aforementioned effects should be taken into account when modeling sales-advertising relationships, most studies have only considered a subset of them. Moreover, previous work has focused on the measurement of short-term effects, rather than on a quantification of the total long-run impact. Multivariate persistence calculations will incorporate all possible channels of influence, enabling one to draw managerially relevant long-run inferences. Also, the resulting model formulation will be largely data-driven, avoiding the need to impose identifying restrictions that may be difficult to justify. 


\section{Modeling unexpected or shock movements}

The second distinctive feature of persistence calculations is their focus on tracing the over-time impact of unexpected movements (shocks), as opposed to more traditional marketresponse models which consider absolute spending or price levels. The shock approach may seem unusual at first, but its underlying logic is quite appealing, and has found support in both the economics and marketing literatures.

A first, important step in any policy analysis is the formulation of a baseline forecast against which policy changes can be evaluated. A logical choice is a no-change scenario in which all historically observed spending and reaction patterns are assumed to persist in the future (Litterman 1984). Within this framework, one-step-ahead sales and advertising forecasts (i.e. $\hat{S}_{t+1}$ and $\hat{A}_{t+1}$ ) can be interpreted as the performance and expenditure levels that are expected on the basis of the available information up to period $t$ (Darnell and Evans 1990; Hanssens 1982). Deviations from the one-step ahead forecasts reflect unexpected shocks, whose differential impact can be traced over time.9

Support for looking at aggregate marketing shocks is found in Helmer (1976), Hanssens (1982) and Kleinbaum (1988). Helmer and Hanssens use univariate ARIMA models to derive expected advertising levels, and include their residuals (i.e. the shocks) instead of the actual spending levels in a market-response model. Their shock operationalization, however, is based on a fairly restrictive information set (i.e. the variable's own past), and multivariate extensions along the lines pursued in this paper were advocated for future research. Kleinbaum, on the other hand, uses the residuals of vector-autoregressive models to characterize competitive reaction patterns in the American truck market. However, all variables in his model were 
mean reverting, precluding the detection of long-run effects.

Further support for a shock approach in measuring marketing effectiveness is found in the individual-choice models developed by Lattin and Bucklin (1989) and Winer (1986). Lattin and Bucklin (1989), for example, use an exponential-smoothing model to derive customerspecific reference-price and/or promotion levels, and deviations between reference and actual levels are shown to have a significant impact on the customer's choice behavior. Since exponential smoothing is a special case of Box and Jenkins' ARIMA model, there is a conceptual link with our approach to measuring long-term effectiveness.

\section{Multivariate persistence estimates}

We use a vector-autoregressive (VAR) model to derive multivariate persistence estimates, because it easily captures multiple channels of influence and does not require the imposition of a priori structural restrictions. ${ }^{10}$

A VAR model on stationary data can be written as:

$$
\vec{X}_{t}=\vec{c}+\sum_{i=1}^{Y} \Pi_{i} \vec{X}_{t-i}+\vec{u}_{t},
$$

where $\vec{X}_{\mathrm{t}}=\mathrm{a}(M \times 1)$ vector of performance and/or marketing variables,

$\Pi_{\mathrm{i}}=\mathrm{a}(M \times M)$ matrix of autoregressive parameters,

$I$ = the order of the VAR model, which may be determined using the well-known

Akaike Information Criterion,

$\vec{c}=\mathrm{a}(M \times 1)$ vector of constants,

$\vec{u}_{1}=\mathrm{a}(M \times 1)$ white-noise vector assumed to be i.i.d. $N(\vec{\sigma}, \Sigma)$.

All elements in $\vec{X}_{t}$ are related to all elements in $\vec{X}_{t-1}(i=1, \ldots, n)$, making VAR models 
especially appropriate for describing the lagged structure in the data, both within and across time series. Contemporaneous effects cannot be captured directly, but information on such effects is contained in the covariance matrix of the residuals $(\Sigma)$. This matrix may be used to detect significant contemporaneous relations, but cannot establish the direction of the effects. Note also that all right-hand side variables are predetermined; hence, no a priori distinction has to be made between endogenous and exogenous variables.

To analyze the impact of unexpected marketing shocks over time, it is useful to introduce the mathematically equivalent vector-moving-average (VMA) representation:

$$
\vec{X}_{t}=\vec{c}+\sum_{k=0}^{\infty} A_{k} \vec{u}_{t-k}
$$

where $A_{0}=I_{\mathrm{M}}$, an $(M \times M)$ identity matrix. The $(i, j)$ th element of $A_{\mathrm{k}}$ gives the impact on $X_{\mathrm{j}, \mathrm{t}}$ (e.g. a brand's sales level) of a one-unit shock that happened $k$ periods ago to variable $j$ (e.g. its advertising support). If the ith variable is stationary, these effects eventually wear out, and the variable returns to its pre-shock mean level. A sequence of successive $(i, j)$ elements is called an impulse-response function, and can be derived either by direct estimation of a truncated VMA model, or by simulating the impact of a shock in a VAR model, which is easier to estimate. For example, to isolate the differential effect of a one-unit advertising shock in a bivariate sales-advertising (S-ADV) model, one can estimate a VAR model, assume both variables equal to zero prior to $t$, and set $\left(u_{s, t}, u_{\mathrm{ADV}, \nu}\right)$ equal to $(0,1)$. Next, one solves recursively for $A D V_{t+k}$ and $S_{1+k}(k=0,1, \ldots)$ under the assumption that no further shocks occur to the system, i.e. assuming $\left(u_{\mathrm{s}, t+\mathrm{k}}, u_{\mathrm{ADV}, t+\mathrm{k}}\right)=(0,0)$ for $k=1,2, \ldots$ This procedure is illustrated in equation (13) for a simple first-order model: 


$$
\left[\begin{array}{c}
S_{t} \\
A D V_{t}
\end{array}\right]=\left[\begin{array}{ll}
\pi_{11} & \pi_{12} \\
\pi_{21} & \pi_{22}
\end{array}\right] *\left[\begin{array}{c}
S_{t-1} \\
A D V_{t-1}
\end{array}\right]+\left[\begin{array}{c}
u_{s, t} \\
u_{A D V, t}
\end{array}\right] .
$$

With the starting conditions given before, the sales and advertising levels in period $t$ become:

$$
\left[\begin{array}{c}
S_{t} \\
A D V_{t}
\end{array}\right]=\left[\begin{array}{ll}
\pi_{11} & \pi_{12} \\
\pi_{21} & \pi_{22}
\end{array}\right] *\left[\begin{array}{l}
0 \\
0
\end{array}\right]+\left[\begin{array}{l}
0 \\
1
\end{array}\right]=\left[\begin{array}{l}
0 \\
1
\end{array}\right] .
$$

Equations (13c)-(13d) give the corresponding values for period $t+1$ and $t+2$ :

$$
\begin{gathered}
{\left[\begin{array}{l}
S_{t+1} \\
A_{t+1}
\end{array}\right]=\left[\begin{array}{ll}
\pi_{11} & \pi_{12} \\
\pi_{21} & \pi_{22}
\end{array}\right] *\left[\begin{array}{l}
0 \\
1
\end{array}\right]+\left[\begin{array}{l}
0 \\
0
\end{array}\right]=\left[\begin{array}{l}
\pi_{12} \\
\pi_{22}
\end{array}\right],} \\
{\left[\begin{array}{l}
S_{t+2} \\
A_{t+2}
\end{array}\right]=\left[\begin{array}{ll}
\pi_{11} & \pi_{12} \\
\pi_{21} & \pi_{22}
\end{array}\right] *\left[\begin{array}{l}
\pi_{12} \\
\pi_{22}
\end{array}\right]+\left[\begin{array}{l}
0 \\
0
\end{array}\right]=\left[\begin{array}{l}
\pi_{11} \pi_{12}+\pi_{12} \pi_{22} \\
\pi_{21} \pi_{12}+\pi_{22} \pi_{22}
\end{array}\right] .}
\end{gathered}
$$

Impulse-response functions reflect the complex and dynamic interactions of all included channels of influence, and provide a complete description of the dynamic structure of the system. When depicted graphically, they are much more comprehensible than the common listings of individual parameter estimates.

When dealing with evolving variables, $\vec{X}$ is replaced by $\Delta \vec{X},{ }^{11}$ and the $(i, j)$ th element in $A_{\mathrm{k}}$ gives the impact of a unit shock on the growth rate of the $i$ th variable. A simulation similar to (13) can be used to trace the over-time impact of a shock to variable $j$ on both the growth rate and the level of variable $i$. In the former case, one solves recursively for $\Delta \mathrm{X}_{i, l+k}$, and in the latter case for $X_{i, e+k}$. The first difference of an evolving variable is stationary, and the corresponding impulse-response function converges to zero. However, the response 
function tracing the over-time effect on the level of an evolving variable can converge to a non-zero level, and this non-zero level corresponds to the multivariate extension of Campbell and Mankiw's $A(1)$ measure (see e.g. Evans 1989).

For ease of exposition and without loss of generality, consider the following bivariate VAR model where both sales and advertising support are evolving: ${ }^{12}$

$$
\left[\begin{array}{cc}
1-\Pi_{11}(L) & -\Pi_{12}(L) \\
-\Pi_{21}(L) & 1-\Pi_{22}(L)
\end{array}\right]\left[\begin{array}{c}
\Delta S_{t} \\
\Delta A D V_{t}
\end{array}\right]=\left[\begin{array}{c}
u_{S, s} \\
u_{A D V, s}
\end{array}\right] ; \quad \operatorname{COV}\left[\begin{array}{c}
u_{S, t} \\
u_{A D V, s}
\end{array}\right]=\mathbf{\Sigma},
$$

The corresponding VMA representation is given by

$$
\left[\begin{array}{c}
\Delta S_{t} \\
\Delta A D V_{t}
\end{array}\right]=\left[\begin{array}{cc}
a_{11}^{0} & a_{12}^{0} \\
a_{21}^{0} & a_{22}^{0}
\end{array}\right]\left[\begin{array}{c}
u_{S, t} \\
u_{A D V, t}
\end{array}\right]+\left[\begin{array}{cc}
a_{11}^{1} & a_{12}^{1} \\
a_{21}^{1} & a_{22}^{1}
\end{array}\right]\left[\begin{array}{c}
u_{S, t-1} \\
u_{A D V, t-1}
\end{array}\right]+\ldots
$$

where $A_{0}=I_{2}$ (i.e. $a_{11}{ }^{0}=a_{22}{ }^{0}=1$ and $a_{21}{ }^{0}=a_{12}{ }^{0}=0$ ). A straightforward generalization of Campbell and Mankiw's $A(1)$ measure suggests $\left(a_{12}{ }^{0}+a_{12}{ }^{1}+a_{12}{ }^{2}+\ldots\right)$ as a measure of the long-run sales impact of a one-unit advertising shock. Indeed, following a similar logic as in the univariate case, $a_{12}{ }^{k}$ measures its impact on the sales growth $k$ periods later, and $\Sigma_{\mathrm{k}}\left(a_{12}{ }^{k}\right)$ gives the long-run impact on the sales level. However, advertising shocks can have an influence on the long-run sales level both directly through the $a_{12}{ }^{k}$, and indirectly through their correlation with $u_{\mathrm{s}, \mathrm{s}}$. The proposed operationalization captures the lagged influences, but omits the instantaneous effect since $a_{12}{ }^{0}=0$. Hence, this operationalization does not reflect the total impact of an incremental advertising outlay. Put differently, when historical data suggest that advertising has an instantaneous effect on sales (as reflected in a significant correlation between $u_{\mathrm{s}, \mathrm{t}}$ and $\left.u_{\mathrm{ADv}, \mathrm{t}}\right)$, it may not be realistic to consider the long-run impact of a change in $u_{\mathrm{ADV}, \mathrm{t}}$ 
alone.

For this reason, persistence calculations are often performed within a transformed VAR model where the error terms have a diagonal covariance matrix, i.e. where there is no instantaneous correlation between the components. Using a Cholesky decomposition, $\Sigma$ can be written as

$$
\Sigma=T^{-1} D\left(T^{-1}\right)^{\prime}
$$

where $D$ is a diagonal matrix, and $T$ an upper triangular matrix with unit diagonal elements. Pre-multiplying (14) by $T$, one gets

$$
\begin{aligned}
\Delta S_{t} & =\gamma \Delta A D V_{t}+\alpha(L) \Delta S_{t-1}+\beta(L) \Delta A D V_{t-1}+e_{S, t} \\
\Delta A D V_{t} & =
\end{aligned}
$$

where $\left(e_{\mathrm{S}, t}, e_{\mathrm{ADV}, \ell}\right)^{\prime}=T\left(u_{\mathrm{S}, l}, u_{\mathrm{ADV},}\right)^{\prime}$. Hence, $e_{\mathrm{ADV}, \mathrm{r}}=u_{\mathrm{ADV}, t}$ and $\operatorname{cov}\left(e_{\mathrm{S}, t}, e_{\mathrm{ADV}, \ell}\right)=0$. The first property implies that a one-unit shock in $e_{\mathrm{ADV}, \mathrm{t}}$ corresponds to a one-unit shock in the original formulation, which avoids the interpretational problems that would arise when the new advertising shock is a linear combination of both $u_{s, t}$ and $u_{\mathrm{ADV}, t}$. The second property eliminates the problem of working with correlated error terms, and ensures the efficiency of OLS to estimate equation (17).

Equation (17) corresponds to a Wold-recursive form in which $A D V_{\mathrm{t}}$ has been assigned causal priority. By ordering advertising first, any contemporaneous correlation between sales and advertising is attributed to the advertising shocks. In other words, we assume that a contemporaneous effect of sales on advertising can be precluded on logical grounds. When advertising is ordered logically prior, $e_{s, t}$ reflects that portion of an unexpected sales increase 
that is not correlated with, or cannot be attributed to, advertising fluctuations.

For a two-variable case, the long-run sales impact of an advertising shock can easily be derived analytically. Rewriting equation (17) in terms of the moving-average representation for $\Delta S_{1}$, one gets (Evans 1989)

$$
\Delta S_{t}=h(L) e_{S, I}+g(L) e_{A D V,}
$$

Using a similar logic as before, $g(1)$ measures the long-run effect on the brand's sales level of a unit advertising shock, and $h(1)$ gives the long-run impact of a unit increase in $e_{\mathrm{s}, \mathrm{t}}$. As shown in Appendix B, $g(1)$ and $h(1)$ are given by

$$
\begin{aligned}
& g(1)=\frac{\gamma+\beta(1)}{[1-\alpha(1)][1-\eta(1)]-\delta(1)[\gamma+\beta(1)]}, \\
& h(1)=\frac{1-\eta(1)}{[1-\alpha(1)][1-\eta(1)]-\delta(1)[\gamma+\beta(1)]} .
\end{aligned}
$$

When more than two variables are involved, an analytical expression for a shock's long-run impact becomes cumbersome to derive. One can, however, use the previously discussed simulation method to trace the entire impulse-response function, and see at what level the series of interest stabilizes. Indeed, $g(1)$ and $h(1)$ correspond to $S_{t+\infty}$ in (17), obtained by "simulating" the over-time impact of, respectively, $\left(u_{\mathrm{s}, \mathrm{r}}, u_{\mathrm{Adv}, \mathrm{t}}\right)$ equal to $(0,1)$ and $\left(u_{\mathrm{s}, \mathrm{l}}, u_{\wedge \mathrm{dr}, \mathrm{t}}\right)$ equal to $(1,0)$.

A potential problem with Campbell and Mankiw's method is the need to impose a causal ordering. If sales (rather than advertising) had been ordered first, different persistence estimates would result, and if contemporaneous effects in both directions exist, any prior ordering is hard to justify. Managerial knowledge will be very important in sorting out this 
issue. Contemporaneous feedback effects were excluded on logical grounds in Carpenter et al. (1988) and Hanssens (1980a), among others. When incorporating competitive marketing-mix instruments, one can often assume that it takes competitors at least one period to react to an unexpected increase in our advertising spending. Hanssens (1980b) analyzed competitive reaction patterns in the U.S. market for domestic air travel, and stated "the model for advertising is necessarily recursive because competitors have no knowledge about each others' advertising expenditures until several quarters after the fact" (p. 482). Finally, it may well be that the residual covariance matrix $\Sigma$ reveals no contemporaneous correlation between two variables. In that case, an imposed ordering should have no significant impact.

Nevertheless, in some situations we may lack prior knowledge about contemporaneous relationships between the variables. In such cases, we could either use different causal orderings and assess the sensitivity of the resulting persistence estimates, or use a persistence operationalization that does not require a prior ordering of the variables. In Appendix A, we introduced Cochrane's $V$ measure, which uses the normalized variance of the series' randomwalk component. A multivariate extension is to use the normalized variance-covariance matrix of the series' random-walk components (see e.g. Dekimpe 1992; Pesaran, Pierse and Lee 1993; Van de Gucht and Kwok 1992). This method requires less prior knowledge, but does not offer a formal link between short- and long-run dynamics.

In conclusion, multivariate persistence is a comprehensive, yet empirically tractable approach to assessing long-term marketing effects in evolving markets. 


\section{A CASE STUDY: THE PERSISTENCE OF MEDIA-MIX EFFECTS}

\subsection{Description of the Data and Research Questions}

Seventy-six monthly observations are available on a large home-improvement chain's sales figures, gross margins, advertising budget, and expenditures on print and TV/radio advertising. All data are expressed in constant 1975 dollars. The chain occasionally buys newspaper space as a third medium to communicate its advertising message. Because of the infrequent spending on newspaper ads, we focus our attention on print and TV/radio advertising.

Print advertising refers to fliers inserted in newspapers, and was used to announce temporary price reductions, so that the duration of its effect should be comparable to the duration obtained when analyzing the over-time impact of price promotions directly. Previous research suggests that promotions often have a substantial immediate effect, and may affect sales in a few subsequent periods through purchase reinforcement. The long-run effects of price promotions have barely been researched, but they seem to be used more for their shortterm effectiveness than as a strategic tool (Blattberg and Neslin 1989; Simon and Sullivan 1990).

Radio and TV advertising, on the other hand, was used primarily to improve the chain's image, and is therefore expected to have longer-lasting effects. A brand's image is believed to be less volatile than its sales or profits, but if there is a relationship between the two, we may see a more persistent impact of TV/radio advertising.

A graph of the sales and total advertising budget is given in Figure 1. In what follows, we apply our framework to answer managerially important questions such as: "Do advertising effects dissipate within one year, or are they persistent? If persistent effects are present, what 
is their relative magnitude? Do media with the highest contemporaneous effect also result in the highest long-run impact? Do the currently used media-allocation rules create short- or long-run synergies?"

We will answer these questions using linear sales-response models. Diminishingreturns-to-scale effects that are common in the advertising-sales relationship are implicitly accounted for by using advertising shocks. For example, the same $\$ 10,000$ in advertising spending would be all shock if historical spending was zero, but would only have a $\$ 4,000$ shock value if historical spending resulted in an expected advertising level of $\$ 6,000$.

Insert Figure 1 about here

\subsection{Are Sales and Advertising Stable or Evolving?}

The unit-root test described in equation (5) was used to separate stable from evolving patterns. As indicated before, the presence of an evolving component in the performance variable is a necessary condition for long-run marketing effectiveness, while the stable/evolving nature of the marketing variables determines what VAR model should be used in the multivariate-persistence calculations. In the test equations, we included seasonal dummy variables to allow for deterministic seasonal effects, ${ }^{13}$ and standard $F$-tests on the coefficients of one, two and three additional lagged differences were used to determine the order of $m$ in (5). The test results are shown in Table $1 .{ }^{14}$

Insert Table 1 about here 
The sales and advertising series all have a long-run or evolving component. Therefore, unexpected changes in the chain's performance have a continuing impact, and VAR models on the differences should be used to quantify the long-run effect of advertising shocks. ${ }^{15}$ The gross margins, on the other hand, are stable: all observed fluctuations are temporary deviations from a fixed mean, and there is no evidence of persistent improvements in the chain's margins.

\subsection{How Important Are the Long-run Sales Fluctuations?}

Having revealed the existence of a long-run component in the company's sales figures, we now quantify its relative importance. Put differently, we already know that the chain's long-run performance forecast should be updated after an unexpected increase (decrease) in current sales, but by how much is still to be determined. We address this question by calculating the sales' univariate persistence.

\section{Insert Table 2 about here}

Table 2A gives Campbell and Mankiw's A(1) measure for several low-order ARMA models. To account for the potentially confounding effects of deterministic seasonal factors, these models were estimated on the residuals of a prior regression of $\Delta S_{\mathrm{t}}$ on seasonal dummy variables rather than on $\Delta S_{\mathrm{t}}$ itself. A similar implementation is found in Pesaran and Samiei (1991). To be able to detect overdifferencing, the order of the moving-average part was at least one and a maximum-likelihood procedure was used which did not preclude the occurrence of a unit root in the MA-polynomial. We estimated all models with $0 \leq p \leq 5$ and $1 \leq q \leq 5$, but report only those models for which 1 ) convergence was obtained after no more than 50 
iterations, and 2) the bounds of stationarity/invertibility were not exceeded in any iteration. Overall, little evidence of overdifferencing was found. For the ARMA(.,1) models, $\theta_{1}$ varied between -1.001 and 0.431 , where overdifferencing would be indicated by a value close to one. For the higher-order models, we checked whether the sum of the moving-average components was close to zero, which would also indicate overdifferencing. This was the case for only one of the models. The low-order ARMA models therefore provide further support for the evolving nature of $S_{t}$.

The overall picture that emerges from Table $2 \mathrm{~A}$ is that approximately $60 \%$ of the initial increase persists in the long run (mean $=0.589),{ }^{16}$ and that about $40 \%$ is temporary. Hence, management should update its long-run sales forecast by approximately $\$ 60,000$ after an unexpected $\$ 100,000$ increase in current performance. Similar values are obtained for the nonparametric estimates $\hat{A}_{\mathrm{k}}(1)$. These robust results increase our confidence in the validity of the findings (see Table 2B).

\subsection{Quantifying the (long-run) Impact of Advertising Shocks}

We now investigate the sources of these long-run sales fluctuations, in particular advertising and its allocation across print and electronic media.

First, we discuss the findings from a bivariate model between sales and the chain's total advertising budget. While such a bivariate analysis does not take into account possible coordinated decision making across the media, it illustrates the methodology in a relatively simple setting. Also, we show how the bivariate impulse-response functions converge to the persistence estimates given in equation (19). Next, we compare the short- and long-run effectiveness of different media in a trivariate framework. 
Do Advertising Pulses Have a Persistent Effect?

Akaike's information criterion was used to determine the order of the VAR response model. The test results are summarized in Table 3, and suggest a VAR model of order two.

\section{Insert Table 3 about here}

Since we know a priori that sales cannot have a contemporaneous feedback effect on advertising, we can uniquely identify the Cholesky decomposition that transforms the VAR model into a system of equations with uncorrelated error terms. ${ }^{17}$ The transformed VAR model is therefore given by ${ }^{18}$

$$
\begin{aligned}
\Delta S_{t} & =\gamma \Delta A D V_{t}+\alpha_{1} \Delta S_{t-1}+\alpha_{2} \Delta S_{t-2}+\beta_{1} \Delta A D V_{t-1}+\beta_{2} \Delta A D V_{t-2}+e_{S, t} \\
\Delta A D V_{t} & =\quad \delta_{1} \Delta S_{t-1}+\delta_{2} \Delta S_{t-2}+\eta_{1} \Delta A D V_{t-1}+\eta_{2} \Delta A D V_{t-2}+e_{A D V, t}
\end{aligned}
$$

This formulation considers instantaneous $(\gamma)$, carry-over $\left(\boldsymbol{B}_{i}\right)$, purchase-reinforcement $\left(\alpha_{i}\right)$ and feedback $\left(\delta_{i}\right)$ effects, as well as historical advertising patterns $\left(\eta_{i}\right)$. The OLS estimates are given in Table 4.

Insert Table 4 about here

However, a more comprehensive summary of the system's dynamics is obtained through a graphical display of the impulse-response functions. Not only does this representation better reflect the dynamic interactions among all included channels, it also quantifies the total long-run impact of advertising shocks. Figure 2 traces the differential 
impact on sales and advertising of a one-unit advertising shock. Figure 2 is derived from a restricted VAR model, in which all coefficients with a $t$-statistic less than one in absolute value have been restricted to zero. The impulse-response functions derived from the unrestricted model are similar in shape, but result in persistence estimates with larger standard errors.

Insert Figure 2 about here

Figure 2 reveals, first, that the impact of advertising shocks extends well beyond the three periods (two lagged differences) that are explicitly included in the VAR model. For example, the incremental sales resulting from advertising's carry-over effect in turn initiate repeat purchases, which explains the increased response in periods three and four. Because of this chain reaction between the different channels of influence, a cyclical sales-response pattern emerges whose fluctuations gradually decrease. Second, the incremental sales and advertising expenditures stabilize at a non-zero level, providing evidence and a quantification of Little's hysteresis effect. An extra advertising dollar in the current period updates the long-run sales forecast by $\$ 1.086,{ }^{19}$ and the long-run advertising forecast by $\$ 0.486$. Thus, as more is spent on advertising in the current period, higher spending levels in future periods become more likely.

At this point, one could argue that the long-run sales impact occurs only because of the additional long-run advertising expenditures. One should, however, focus on the shock's net long-run impact $(0.600)$ rather than on its total sales persistence (1.086). This net effect suggests that the current advertising investment results in a positive dollar inflow in the long run. 
What about the long-run profitability of advertising spending? Given a sales persistence of 1.086, and a long-run advertising impact of 0.486 , the required margin to break even is 0.448 (i.e. $0.486 / 1.086$ ). Gross margins behave in a stable way, which implies that the sample mean $(=0.348)$ is their best long-run forecast. Therefore, even though advertising has a positive net sales effect, it does not have a positive long-run profit impact.

Finally, $h(1)$ reflects the long-run impact of an unexpected sales increase that cannot be attributed to advertising. For the restricted VAR(2) model, a value of 0.760 is obtained. This measure can be interpreted as a first estimate of the long-run impact of competitive activities: if competition erodes sales instantaneously by $\$ 100,000$, management should adjust its long-run sales forecast by $-\$ 76,000$. Since $e_{\mathrm{s}, \mathrm{t}}$ and $e_{\mathrm{ADV}, t}$ are uncorrelated, we assume implicitly that there is no instantaneous advertising reaction to the competitive shock. We also emphasize that $h(1)$ is the best estimate of the long-run impact of competition, based on the available information. Clearly, we could obtain better estimates if competitive spending were added to the information set.

\section{Do Print and TVIRadio Pulses Have a Different Short- and Long-run Effectiveness?}

Based on the AIC criterion, a second-order model was selected to assess the impact of print and TV/radio expenditures on sales (see Table 3). The VAR specification allows us to test for two types of coordinated media decision making: spending levels in one medium may affect the level in the other medium either instantaneously or in one of the subsequent periods. For example, TV/radio advertising could be used first to improve awareness and/or quality perception, followed by print advertisements announcing temporary price reductions to capitalize on these improvements. Instantaneous effects are reflected in the residual correlation 
matrix. For an unrestricted VAR(2) model, the correlation between print and TV/radio was only 0.020 and not significant $(t=0.174)$. Wald tests were used to check for lagged effects, but none turned out to be significant. In the print-advertising equation, the chi-square coefficient for testing the joint significance of the TV/radio coefficients was 2.615 $\left(\mathrm{X}^{2}{ }_{0.95}(2)=5.991\right)$. A value of 2.218 was obtained for a comparable test in the TV/radio equation. Hence, there is no evidence of a coordinated media-allocation strategy. Since there is no (significant) contemporaneous correlation between both series, the imposed causal ordering should have no major impact on the resulting persistence estimates. In what follows, we assume that the medium that is "shocked" is ordered first, and assess the sensitivity of our findings to this assumption. Sales are always ordered last, since they cannot realistically feed back into media spending in the same period. The impulse-response functions derived from the restricted and transformed VAR(2) models are given in Figure 3. Table 5 summarizes the resulting persistence estimates..$^{20}$

Insert Figure 3 and Table 5 about here

When comparing the short- and long-run effectiveness of both media, the following observations can be made. First, even though print advertising has a significant instantaneous impact, no positive net long-run impact is observed. After an unanticipated $\$ 100,000$ increase in the chain's current spending on print advertising, the long-run sales forecast is updated by $\$ 9,400$ while the long-run print-advertising forecast is updated by $\$ 44,200$. This provides empirical support for the notion that sales promotions (as announced by print advertisements) may be useful from a short-term sales or profit point of view, but could be harmful to the 
brand's long-run performance. The image-oriented TV/radio messages, on the other hand, do not have a significant instantaneous impact (their coefficient is even set to zero in the restricted model specification), but result in a much larger long-run impact. Indeed, even though the TV/radio forecast is updated by an amount $(\$ 48,000)$ similar to the print-advertising forecast $(\$ 44,200)$, the long-run sales forecast is now adjusted by $\$ 74,100$. These examples clearly illustrate that the total long-run sales effect cannot be explained solely in terms of increased advertising spending.

We also see that the long-run forecast of the spending level in one medium is only marginally affected by an unexpected increase in the other medium. We retained this rather weak joint-decision-making effect in the restricted VAR(2) specification because the absolute value of the $t$-statistic slightly exceeded one. ${ }^{21}$ Next, the long-run sales impact of a unit shock

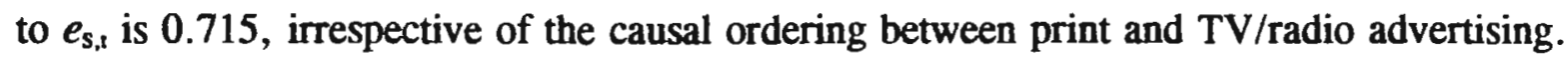
This figure can be interpreted as an indication of the long-run impact of other determinants of chain sales, such as competitive shocks. Over 70 percent of the instant effects of such shocks persist in the long run. Insofar as these effects are negative, they imply that management must be constantly alert and be prepared to react.

As a final comment on the empirics, it is important to realize that the various shocks and their persistence may all affect sales at the same time. So, when we argue, for example, that $60 \%$ of advertising shock effects are permanent, we do not imply that this persistence on sales will actually occur. Other shocks are likely to also affect sales, and these may amplify or diminish the long-run advertising effect. Our analyses, however, have disentangled the various sources of long-run movements in sales in a way that allows us to compare their relative magnitude and make managerially important inferences. 


\section{CONCLUSION - AREAS FOR FUTURE RESEARCH}

We have introduced a new approach to measure the long-run effectiveness of marketing, called persistence modeling. It differs from traditional methods in that it computes the total long-run impact of unexpected shocks in any marketing variable. Persistence modeling satisfies our three criteria for long-run effectiveness measures: (1) it quantifies the long-run impact of deviations from a brand's expected marketing support, (2) it distinguishes long-run marketing impact in stable versus evolving environments, and (3) it provides a formal link between marketing's short-term and long-run effect.

We discussed the different steps of the proposed framework in some detail and used them to compare the short- and long-run effectiveness of the advertising media used by a large home-improvement chain. Several managerially relevant conclusions emerged from our analyses. First, advertising effects did not dissipate within one year, but had a persistent effect on the chain's sales evolution. This finding differs from Clarke's (1976) conclusion, based on traditional market-response models, that $90 \%$ of the measurable effects of advertising on sales are consumed within three to nine months after the expenditure. Our findings suggest that Clarke's conjecture may be valid in stationary environments, but should not be generalized to evolving markets. Hence, if the distinct nature of evolving environments is not explicitly taken into account, one may seriously underestimate the long-run effectiveness of advertising.

Second, our multivariate persistence estimates provide empirical support for Little's hysteresis effect. To the best of our knowledge, this study is the first to quantify this concept using ETS models. Third, a long-run positive net sales effect was observed only for TV/radio pulses. This confirmed our prior expectations, and provided empirical support for the conjecture that a growing emphasis on sales promotions may not be helpful to a brand's long-run performance. 
Fourth, no evidence was found in support of a coordinated media-allocation strategy, suggesting that this particular company has some unexplored opportunities for creating shortor long-run synergies.

Possible areas for future research remain wide open. First, more work is needed on the dynamic optimization of shock-based marketing strategies. Several studies have compared the short-term performance impact of pulsed and even (i.e. constant-spending) advertising policies (see e.g. Mahajan and Muller 1986). However, these studies considered only the short-term implications of the different spending patterns, and did not explicitly model the expected/unexpected nature of the pulse. Doing so may require a different concept of optimal marketing behavior. Indeed, repeated unexpected shocks may affect the baseline forecast down the line, and may influence what is considered unexpected in the future (see e.g. Winer 1986). Second, the study of temporal aggregation biases may receive a new impetus: the presence or absence of unit roots is not affected by the level of aggregation, and disaggregate univariate persistence estimates can be derived from their aggregate counterparts (see e.g. Dekimpe 1992). More research is needed, however, to see whether this also holds for their multivariate extensions. Finally, we only considered one case study. More data sets should be analyzed in order to derive empirical generalizations on the differential long-run effectiveness of promotions, image-oriented advertising and other marketing efforts.

We conclude by revisiting our opening example of sports-car sales. The first question facing dealers, is the downturn in sales of a permanent or temporary nature, can be answered by testing for unit roots in the time series of sports-car sales. If there are no unit roots, we have little to say about long-run sales movements and we can only make short-term inferences about marketing effects. However, if evolution is established, we can test to what extent long- 
run sales of sports cars are affected by marketing strategies such as advertising spending and price levels, by calculating the appropriate persistence measures. This new knowledge can be put to good use in the design of marketing strategies that create a sustainable competitive advantage. 


\section{FOOTNOTES}

1. We do not intend to give a complete review of the literature on distributed-lag models. Rather, we use the popular Koyck specification to assess the usefulness of this research tradition in studying long-run phenomena. We refer to Hanssens et al. (1990) for a more detailed discussion of distributed-lag models.

2. Applications include studies that assess the persistence of first-mover advantages (Urban et al. 1986), the relationship between ROI and market share (Boulding and Staelin 1990) and between profitability and market structure (Bass, Cattin and Wittink 1978), among others.

3. We focus on the stable/evolving nature of sales performance, since this determines whether or not long-run marketing effects are possible. Evolution in marketing spending is neither a necessary nor a sufficient condition for long-run marketing effectiveness, but determines what modeling strategy should be used to derive multivariate persistence estimates. Hence, unit-root tests should also be applied to the marketing time series.

4. Evolving patterns may also arise because of seasonal factors. Consider, for example, the seasonal equivalent of equation (1): $\left(1-\phi_{\mathrm{d}} L^{\mathrm{d}}\right) S_{\mathrm{t}}=c+u_{\mathrm{l}}$, where $d$ equals 4 for quarterly observations and 12 for monthly data. Sales are seasonally evolving when $\left|\phi_{\mathrm{d}}\right|=1$. Tests for seasonal unit roots are similar in spirit to regular unit-root tests, but require different critical values. We refer to Dekimpe (1992) for a recent review.

5. Because of the additional lagged dependent variables, this test is often called the "augmented" Dickey-Fuller (ADF) test. An important issue in applying the ADF test is the choice of the maximum lag length $m$. Setting $m$ too high results in a less powerful test. On the other hand, an $m$ value that is too small may fail to make the $u_{-}$-series white noise and results in a biased test statistic. Following Evans (1989) and Perron (1990), we use conventional significance tests on the $a_{\mathrm{i}}$ to empirically determine the cut-off point.

6. The error terms (or shocks) in a univariate ARIMA-model can be interpreted as deviations from the series' expected level (Hanssens 1982). The information set used in this expectation formation, however, is restricted to the series own past history. Extensions that incorporate information from other variables are discussed in Section 3.4.

7. Each combination of $p$ and $q$ (i.e. the order of the autoregressive and moving-average polynomials) provides a somewhat different approximation to the infinite-shock representation of $\Delta S_{\mathrm{h}}$, and may result in somewhat different persistence estimates. One could try to determine the "best" model specification using likelihood-ratio tests on nested specifications, a visual inspection of the series' low-order autocorrelations, the Akaike or Schwartz criterion, etc... (Campbell and Mankiw 1987b). An alternative approach is to look at the overall picture that arises from several ARMA models. Finally, one can estimate $A(1)$ non-parametrically. A procedure that does not require any model specification is described in Appendix A, and can be used to validate the parametric 
estimates from low-order ARMA models.

8. The importance of modeling the firm's decision behavior when making inferences about advertising carry-over is also emphasized by Russell (1988). Using an exogenous and stationary ARMA process to describe the firm's advertising behavior, he derived a Generalized Koyck model in an attempt to get more robust (i.e. less sensitive to aggregation biases) carry-over estimates.

9. Obviously, changes in the information set will affect the baseline forecast and the shock level of a given marketing expenditure. Also, different market participants may have different baseline forecasts, and a marketing action may be a shock to some but not to others: a marketing effort may be the expected level for the firm, but may not have been fully anticipated by its competitors. The firm will not update its long-run performance forecast, but the competitors should revise their forecast of the same variable.

10. See Sims (1980) for a formal development, and Kleinbaum (1988) or Moriarty (1985) for marketing applications.

11. If both stable and evolving variables are present, a mixed model in both levels and differences is estimated.

12. For ease of exposition, we have omitted in equation (13) all deterministic components (e.g. constants or seasonal dummy variables). These are not important when computing the differential impact of marketing shocks. Obviously, to estimate the parameters and to derive a baseline forecast, an intercept or seasonal dummies should be included.

13. Ghysels, Lee and Noh (1991) show that a failure to account for deterministic seasonal effects distorts the test results when these effects are present in the data-generating process: a bias is introduced in the size of the test, while there is also a considerable power reduction. Including redundant seasonal dummy variables also tends to reduce the power of the test, but to a much lesser extent than their erroneous omission.

14. We also tested for the presence of seasonal unit roots, but this null hypothesis was firmly rejected in all cases. The test results are available from the authors upon request.

15. Johansen's FIML approach was used to test for a cointegrating relationship between performance and control series (Johansen 1988), but no such relationship was found. If a cointegrating relationship is present, an error-correction VAR model should be used to derive the impulse-response functions. Because of space limitations, we do not elaborate on these concepts in this paper, and refer to Dekimpe (1992) and Powers, Hanssens, Hser and Anglin (1991) for a detailed exposition.

16. We also considered the models for which the bounds of invertibility/stationarity had been exceeded at some iteration, and obtained similar findings. For example, the range of obtained values $[0.545 ; 0.764]$ remained the same, while the mean value became 0.648 . However, the estimated standard errors of these models were substantially larger than for 
the models included in Table $2 \mathrm{~A}$.

17. In what follows, we still refer to the transformed model as a VAR(2) system, even though it contains a contemporaneous effect in one of the equations. The context of our subsequent discussion should preclude any confusion on whether we are dealing with the original VAR(2) specification (without explicit contemporaneous advertising effects but with correlated error terms) or with the transformed system.

18. Seasonal dummy variables were also included, but are omitted for ease of presentation.

19. This figure was derived in two ways: through a simulation of the response function and by a straightforward substitution of the different parameter estimates into equation (19a). Asymptotic standard errors were derived using the delta method, and the resulting $t$ statistics are $3.271,10.130$ and 1.935 for the long-run impact on the sales series, on the advertising series and for the net effect, respectively.

20. Note that the long-run sales impact of both the print shock $(0.094)$ and the TV/radio shock $(0.741)$ is smaller than the value obtained in the restricted bivariate model (1.086). A number of factors should be taken into account when interpreting these findings. First, we know ex post that the bivariate model is misspecified, since two media with different instantaneous and over-time effectiveness are combined. Second, when looking at the unrestricted bivariate model, a sales persistence of 0.874 was obtained, which is similar to the value obtained for the TV/radio shock $(0.741)$. Hence, depending on the treatment of the insignificant effects, somewhat different persistence estimates may result. Following Pesaran et al. (1993), a conservative approach was adopted and we omitted all coefficients with a $t$-statistic less than one in absolute value. Third, even when looking at the restricted bivariate model (with a sales persistence of 1.086), we see that the persistence estimate of the TV/radio shock $(0.741)$ is included in its $95 \%$ confidence interval.

21. An update in the long-run forecast of the medium that was not shocked could also be caused by feedback effects. In this particular application, these coefficients all had $t$ values less than one in absolute value. 


\section{REFERENCES}

Abraham, Magid M. and Leonard M. Lodish (1991), "Fact-Based Strategies for Managing Advertising and Promotion Dollars: Lessons from Single Source Data, " Paper presented at the first UCLA Symposium on Advertising Research, Los Angeles, CA.

Bass, Frank M. (1969), "A Simultaneous Equation Regression Study of Advertising and Sales of Cigarettes," Journal of Marketing Research, 6 (August), 291-300.

Bass, Frank M., Philippe Cattin and Dick R. Wittink (1978), "Firm Effects and Industry Effects in the Analysis of Market Structure and Profitability," Journal of Marketing Research, 15 (February), 3-10.

Bass, Frank M. and Darral G. Clarke (1972), "Testing Distributed Lag Models of Advertising Effect," Journal of Marketing Research, 9 (August), 298-308.

Bass, Frank M. and Leonard J. Parsons (1969), "A Simultaneous Equation Regression Analysis of Sales and Advertising," Applied Economics, 1 (May), 103-124.

Blattberg, Robert C. and Scott A. Neslin (1989), "Sales Promotions: The Long and the Short of It, "Marketing Letters, 1 (1), 81-97.

Boulding, William and Richard Staelin (1990), "Environment, Market Share, and Market Power," Management Science, 36 (October), 1160-1177.

Campbell, John Y. and N. Gregory Mankiw (1987a), "Permanent and Transitory Components in Macroeconomic Fluctuations," American Economic Review (Papers and Proceedings), 77 (May), 111-117.

Campbell, John Y. and N. Gregory Mankiw (1987b), "Are Output Fluctuations Transitory?" Quarterly Joumal of Economics, 102 (November), 857-880.

Carpenter, Gregory S., Lee G. Cooper, Dominique M. Hanssens and David F. Midgley (1988), "Modeling Asymmetric Competition," Marketing Science, 7 (Fall), 393-412.

Clarke, Darral G. (1976), "Econometric Measurement of the Duration of Advertising Effect on Sales," Journal of Marketing Research, 13 (November), 345-357.

Cochrane, John H. (1988), "How Big is the Random Walk Component in GNP?" Journal of Political Economy, 96 (5), 893-920.

Darnell, Adrian C. and J. Lynne Evans (1990), The Limits of Econometrics, Edward Elgar.

Dekimpe, Marnik G. (1992), "Long-run Modeling in Marketing," Unpublished Doctoral Dissertation, University of California, Los Angeles. 
Dickey, David A. and Wayne A. Fuller (1979), "Distribution of the Estimators for Autoregressive Time Series with a Unit Root, "Journal of the American Statistical Association, 74 (June), 427-431.

Diebold, Francis X. and Marc Nerlove (1990), "Unit Roots in Economic Time Series: A Selective Survey," in Fomby, T.B. and G.F. Rhodes (eds.), Advances in Econometrics, 8, 3-69.

Evans, George W. (1989), "Output and Unemployment Dynamics in the United States," Joumal of Applied Econometrics, 4 (July-September), 213-237.

Fuller, Wayne A. (1976), Introduction to Statistical Time Series, New York: Wiley.

Ghysels, Eric, Hahn S. Lee and Jaesun Noh (1991), "Testing for Unit Roots in Seasonal Time Series: Some Theoretical Extensions and a Monte Carlo Investigation," Working Paper, Département de Sciences Economiques, Université de Montréal.

Givon, Moshe and Dan Horsky (1990), "Untangling the Effects of Purchase Reinforcement and Advertising Carryover," Marketing Science, 9 (Spring), 171-187.

Hanssens, Dominique M. (1980a), "Bivariate Time Series Analysis of the Relationship Between Advertising and Sales," Applied Economics, 12 (September), 329-340.

Hanssens, Dominique M. (1980b), "Market Response, Competitive Behavior, and Time Series Analysis," Journal of Marketing Research, 17 (November), 470-485.

Hanssens, Dominique M. (1982), "Expectations and Shocks in Market Response," Center for Marketing Studies Working Paper No. 123, The Anderson Graduate School of Management, University of California, Los Angeles.

Hanssens, Dominique M., Leonard J. Parsons and Randall L. Schultz (1990), Market Response Models: Econometric and Time Series Analysis, Boston: Kluwer Academic Publishers.

Helmer, Richard M. (1976), "New Experimental and Quasi- Experimental Designs for Estimating Lagged Effects of Advertising Directly," 1976 Educator's Proceedings, American Marketing Association, 478-482.

Helmer, Richard M. and Johny K. Johansson (1977), "An Exposition of the Box Jenkins Transfer Function Analysis with an Application to the Advertising-Sales Relationship," Journal of Marketing Research, 14 (May), 227-239.

Horsky, Dan and Leonard S. Simon (1983), "Advertising and the Diffusion of New Products," Marketing Science, 7 (Fall), 356-367.

Johansen, Soren (1988), "Statistical Analysis of Cointegration Vectors, " Journal of Economic 
Dynamics and Control, 12 (June/September), 231-254.

Johnson, Tod (1984), "The Myth of Declining Brand Loyalty," Journal of Advertising Research, 24 (February-March), 9-17.

Kamakura, Wagner and Gary Russell (1991), Measuring Consumer Perceptions of Brand Quality with Scanner Data: Implications for Brand Equity, Marketing Science Institute Report 91-22, Cambridge, MA.

Kleinbaum, Robert M. (1988), Multivariate Time Series Forecasts of Market Share, Marketing Science Institute Report 88-102, Cambridge, MA.

Lambkin, Mary and George S. Day (1989), "Evolutionary Processes in Competitive Markets: Beyond the Product Life Cycle," Journal of Marketing, 53 (July), 4-20.

Lattin, James M. and Randolph E. Bucklin (1989), "Reference Effects of Price and Promotion on Brand Choice Behavior," Journal of Marketing Research, 26 (August), 299-310.

Leone, Robert P. (1987), "Forecasting the Effect of an Environmental Change on Market Performance: An Intervention Time-Series Approach," International Journal of Forecasting, 3 (3/4), 463-478.

Leone, Robert P. and Randall L. Schultz (1980), "A Study of Marketing Generalizations," Journal of Marketing, 44 (Winter), 101-118.

Litterman, Robert B. (1984), "Forecasting and Policy Analysis With Bayesian Vector Autoregression Models, "Federal Reserve Bank of Minneapolis Quarterly Review, 8 (Fall), 30-41.

Little, John D.C. (1979), "Aggregate Advertising Models: The State of the Art," Operations Research, 27 (July-August), 629-667.

Louviere, Jordan and Richard Johnson (1988), "Measuring Brand Image with Conjoint Analysis and Choice Models," in Leuthesser, Lance (ed.), Defining, Measuring, and Managing Brand Equity, Marketing Science Institute Report 88-104, Cambridge, MA.

Mahajan, Vijaj and Eitan Muller (1986), "Advertising Pulsing Policies for Generating Awareness for New Products," Marketing Science, 5 (Spring), 89-11.

Metwally, M.M. (1978), "Escalation Tendencies of Advertising," Oxford Bulletin of Economics and Statistics, 40 (May), 153-163.

Moriarty, Mark M. (1985), "Design Features of Forecasting Systems Involving Management Judgments, " Journal of Marketing Research, 22 (November), 353-364. 
Palda, Kristian S. (1964), The Measurement of Cumulative Advertising Effects, Englewood Cliffs, NJ: Prentice-Hall.

Perron, Pierre (1990), "Testing for a Unit Root in a Time Series With a Changing Mean," Journal of Business and Economic Statistics, 8 (April), 153-162.

Pesaran, M. Hashem, Richard G. Pierse and Kevin C. Lee (1993), "Persistence, Cointegration and Aggregation: A Disaggregated Analysis of Output Fluctuations in the U.S. Economy," Journal of Econometrics, forthcoming.

Pesaran, M. Hashem and Hossein Samiei (1991), "Persistence, Seasonality and Trend in UK Egg Production," Applied Economics, 23 (March), 479-484.

Powers, Keiko I., Dominique M. Hanssens, Yih-Ing Hser and M. Douglas Anglin (1991), "Measuring the Long-Term Effects of Public Policy: The Case of Narcotics Use and Property Crime," Management Science, 37 (June), 627-644.

Russell, Gary J. (1988), "Recovering Measures of Advertising Carryover From Aggregate Data: The Role of the Firm's Decision Behavior," Marketing Science, 7 (Summer), 252-270.

Simon, Carol J. and Mary W. Sullivan (1993), "The Measurement and Determinants of Brand Equity: A Financial Approach," Marketing Science, forthcoming.

Sims, Christopher A. (1980), "Macroeconomics and Reality," Econometrica, 48 (1), 1-48.

Spanos, Aris (1986), Statistical Foundations of Econometric Modelling, Cambridge: Cambridge University Press.

Stock, James H. and Mark Watson (1988), "Variable Trends in Economic Time Series," Journal of Economic Perspectives, 2 (Summer), 147-174.

Urban, Glen L., Theresa Carter, Steve Gaskin and Zofia Mucha (1986), "Market Share Rewards to Pioneering Brands: An Empirical Analysis and Strategic Implications," Management Science, 32 (June), 645-659.

Van de Gucht, Linda M. and Chuck Y. Kwok (1992), "Persistence in Foreign Exchange Rates," Center for International Business Education and Research Working Paper No. D-93-02, University of South Carolina.

Winer, Russell S. (1986), "A Reference Price Model of Brand Choice for Frequently Purchased Products," Joumal of Consumer Research, 13 (September), 250-256. 


\section{APPENDIX A}

A somewhat different measure of persistence has been proposed by Cochrane (1988), and is defined by the variance ratio

$$
\begin{aligned}
V_{k} & =[1 /(k+1)] \operatorname{Var}\left(S_{t+k+1}-S_{t}\right) / \operatorname{Var}\left(S_{t+1}-S_{t}\right) \\
& =1+2 \sum_{j=1}^{k}\{1-[j /(k+1)]\} \rho_{j},
\end{aligned}
$$

where $\rho_{j}$ is the $j$ th autocorrelation of $\Delta S_{h}$. Any series with a unit root can be written as the sum of a random walk and a stationary process, in which the former (latter) carries the permanent (temporary) part of a shock to the series. ${ }^{1}$ The ratio of the variance in the random-walk part to the variability in the one-period changes reflects the importance of the random-walk or permanent component to the behavior of the series. This variance ratio equals the limiting value ( $V$ ) of $V_{\mathrm{k}}$ (for $k$ going to infinity), and can be approximated by choosing a finite $k$-value. For a random walk, the variance of the $(k+1)$-lagged differences (i.e. the numerator in equation (A.1) is $(k+1)$ times the variance of the once-lagged differences. Hence, $V_{k}$ will equal one. For a stationary series, the variances do not depend on $k$, and $V_{\mathrm{k}}$ approaches zero for large $k$. Cochrane's $V$ - and Campbell and Mankiw's $A(1)-$ measure are therefore equal for pure random-walk and stationary processes. In all other cases, $V^{1 / 2}$ is a lower bound for $A(1)$, and both measures are related by

$$
A(1)=\left[V /\left(1-R^{2}\right)\right]^{1 / 2},
$$

where $R^{2}=1-\operatorname{Var}\left(e_{t}\right) / \operatorname{Var}\left(\Delta S_{t}\right)$, the fraction of the variance of $\Delta S_{t}$ explained by a simple

1. See Stock and Watson (1988) for a mathematical proof. It should be noted that this decomposition is not unique. It can be shown, however, that the variance ratio of interest is not affected by the selected decomposition. 


\begin{abstract}
ARIMA model. Equation (A.2.) can be used to derive a nonparametric estimate of $A(1)$ : a consistent estimate for $V_{\mathrm{k}}$ is obtained by replacing $\rho_{\mathrm{j}}$ with its sample counterpart $\hat{\rho}_{\mathrm{j}}$ in equation (A.1), and $\hat{\rho}_{1}^{2}$ can be used as a conservative estimate of $R^{2}$. Obviously, the obtained nonparametric estimate depends on $k$, the number of autocorrelations in equation (A.1). In the empirical application, estimates are reported for different values of $k$, which allows us to assess the robustness of our findings. We refer to Dekimpe (1992) for a more detailed discussion on Cochrane's procedure.
\end{abstract}


Starting from equation (17),

$$
\begin{gathered}
\Delta S_{t}=\gamma \Delta A D V_{t}+\alpha(L) \Delta S_{t-1}+\beta(L) \Delta A D V_{t-1}+e_{S, t} \\
\Delta A D V_{t}=\quad \delta(L) \Delta S_{t-1}+\eta(L) \Delta A D V_{t-1}+e_{A D V, t}
\end{gathered}
$$

one can combine terms to get

$$
\begin{aligned}
{[1-\alpha(L) L] \Delta S_{t} } & =[\gamma+\beta(L) L] \Delta A D V_{t}+e_{S, t} \\
{[1-\eta(L) L] \Delta A D V_{t} } & =[\delta(L) L] \Delta S_{t}+e_{A D V, t}
\end{aligned}
$$

(B.4) can be rewritten as

$$
\Delta A D V_{t}=\frac{\delta(L) L}{1-\eta(L) L} \Delta S_{t}+\frac{1}{1-\eta(L) L} e_{A D V_{t}}
$$

Substituting (B.5) into (B.3), we get

$$
[1-\alpha(L) L] \Delta S_{t}=\frac{[\gamma+\beta(L) L][\delta(L) L]}{1-\eta(L) L} \Delta S_{t}+\frac{\gamma+\beta(L) L}{1-\eta(L) L} e_{A D V_{t}}+e_{S, t}
$$

which can be rewritten as

$$
\Delta S_{t}=h(L) e_{S, t}+g(L) e_{A D V, t}
$$

where

$$
\begin{aligned}
& h(L)=\frac{1-\eta(L) L}{[1-\alpha(L) L][1-\eta(L) L]-[\gamma+\beta(L) L][\delta(L) L]} \\
& g(L)=\frac{\gamma+\beta(L) L}{[1-\alpha(L) L][1-\eta(L) L]-[\gamma+\beta(L) L][\delta(L) L]}
\end{aligned}
$$

(B.8) and (B.9) result in equation (19) after substituting 1 for $L$. 
TABLE 1

TESTING FOR A LONG-RUN COMPONENT: ADF-TEST

\begin{tabular}{|c|c|c|c|c|c|c|}
\hline Series & t-stat. $^{1}$ & $\mathrm{~m}$ & $\mathrm{~F}(1,)$. & $\mathrm{F}(2,)$. & $\mathrm{F}(3,)$. & Unit Root? \\
\hline sales & -0.64 & 1 & 0.69 & 0.54 & 0.60 & yes \\
adv. & -2.04 & 2 & 0.75 & 1.16 & 0.84 & yes \\
print & -2.33 & 2 & 0.96 & 1.17 & 0.85 & yes \\
TV/radio & -2.15 & 2 & 0.56 & 1.01 & 0.80 & yes \\
margin & -3.51 & 0 & 3.10 & 1.76 & 1.17 & no \\
\hline
\end{tabular}

The $5 \%$ critical value is -2.89 . The F-statistics in colums four to six test the significance of one to three additional lagged differences. We also tested for a second unit root, but no such evidence was found. 
TABLE 2A

PARAMETRIC PERSISTENCE ESTIMATES FOR THE SALES SERIES

\begin{tabular}{|c|c|c|}
\hline$(p, q)$ & $A(1)$ & S.e. $[A(1)]$ \\
\hline$(0,1)$ & 0.570 & 0.106 \\
\hline$(0,2)$ & 0.570 & 0.126 \\
\hline$(0,3)$ & 0.557 & 0.148 \\
\hline$(0,4)$ & 0.646 & 0.166 \\
\hline$(0,5)$ & 0.764 & 0.187 \\
\hline$(1,1)$ & 0.570 & 0.126 \\
\hline$(1,3)$ & 0.555 & 0.149 \\
\hline$(1,4)$ & 0.696 & 0.214 \\
\hline$(1,5)$ & 0.717 & 0.187 \\
\hline$(3,1)$ & 0.563 & 0.128 \\
\hline$(4,1)$ & 0.545 & 0.098 \\
\hline$(5,1)$ & 0.649 & 0.224 \\
\hline & $\begin{aligned} \text { Mean } & =0.589 \\
\text { Median } & =0.569\end{aligned}$ & \\
\hline
\end{tabular}


TABLE 2B

NONPARAMETRIC PERSISTENCE ESTIMATES FOR THE SALES SERIES

\begin{tabular}{|c|c|c|}
\hline $\mathrm{k}$ & $\hat{V}_{\mathrm{k}}$ & $\hat{A}_{\mathrm{k}}(1)$ \\
\hline 6 & 0.397 & 0.678 \\
12 & 0.308 & 0.597 \\
18 & 0.257 & 0.545 \\
\hline
\end{tabular}

TABLE 3

SELECTION OF THE ORDER OF THE VAR MODELS ${ }^{1}$

\begin{tabular}{|c|c|c|}
\hline \multicolumn{3}{|c|}{ AKAIKE INFORMATION CRITERION } \\
\hline order I & S-A & S-P-TV/R \\
\hline 1 & 49.733 & 37.199 \\
2 & 49.465 & 36.631 \\
3 & 49.291 & 36.334 \\
4 & 49.343 & 36.513 \\
5 & 49.415 & 36.602 \\
\hline
\end{tabular}

$\mathrm{S}-\mathrm{A}=$ sales and total advertising budget; S-P-TV/R = a model with sales, print advertising and television advertising. All figures are computed on the same number of observations. 
TABLE 4

OLS ESTIMATES FOR THE SALES-ADVERTISING MODEL ${ }^{1}$

\begin{tabular}{|c|c|c|}
\hline & Unrestricted VAR(2) & Restricted VAR(2) \\
\hline$\alpha_{1}$ & $1.818(3.132)$ & $1.910(3.793)$ \\
$\alpha_{2}$ & $-0.460(3.442)$ & $-0.429(3.646)$ \\
$B_{1}$ & $-0.102(0.765)$ & 0 \\
$B_{2}$ & $1.194(1.732)$ & $1.280(2.345)$ \\
$\delta_{1}$ & $-0.161(0.240)$ & 0 \\
$\delta_{2}$ & $0.041(1.356)$ & $0.041(1.356)$ \\
$\eta_{1}$ & $0.038(1.256)$ & $0.038(1.256)$ \\
$\eta_{2}$ & $-0.674(5.205)$ & $-0.674(5.205)$ \\
\hline
\end{tabular}

The figures between parentheses are the absolute value of the associated $t$-statistics. In the restricted model, all coefficients with a $t$-value less than one in absolute value have been restricted to zero. 
TABLE 5

PERSISTENCE CALCULATIONS IN A TRIVARIATE MODEL ${ }^{1}$

\begin{tabular}{|c|c|}
\hline \multicolumn{2}{|c|}{ A. Impact of a unit shock to print advertising } \\
\hline Persistent effect on sales & 0.094 \\
\hline Persistent effect on print adv. & 0.442 \\
\hline Persistent effect on TV $\backslash$ radio adv. & -0.017 \\
\hline Net long-run effect & -0.331 \\
\hline \multicolumn{2}{|c|}{ B. Impact of a unit shock to TV/Radio advertising } \\
\hline Persistent effect on sales & 0.741 \\
\hline Persistent effect on print adv. & 0.075 \\
\hline Persistent effect on TV \radio adv. & 0.480 \\
\hline Net long-run effect & 0.186 \\
\hline \multicolumn{2}{|c|}{ C. Impact of a unit shock to sales } \\
\hline Persistent effect on sales & 0.715 \\
\hline Persistent effect on print adv. & 0.023 \\
\hline Persistent effect on TV/radio adv. & -0.001 \\
\hline
\end{tabular}

All figures are based on a restricted VAR(2) model. In panel A, print advertising is ordered first, and in panel B TV/radio advertising is ordered first. The figures in panel $\mathrm{C}$ are obtained irrespective of the ordering between print and TV/radio advertising. The sales series is always ordered last. Overall, the causal ordering of both advertising media did not have a significant impact, and affected only the last digit of the persistence estimates. 
FIGURE 1A

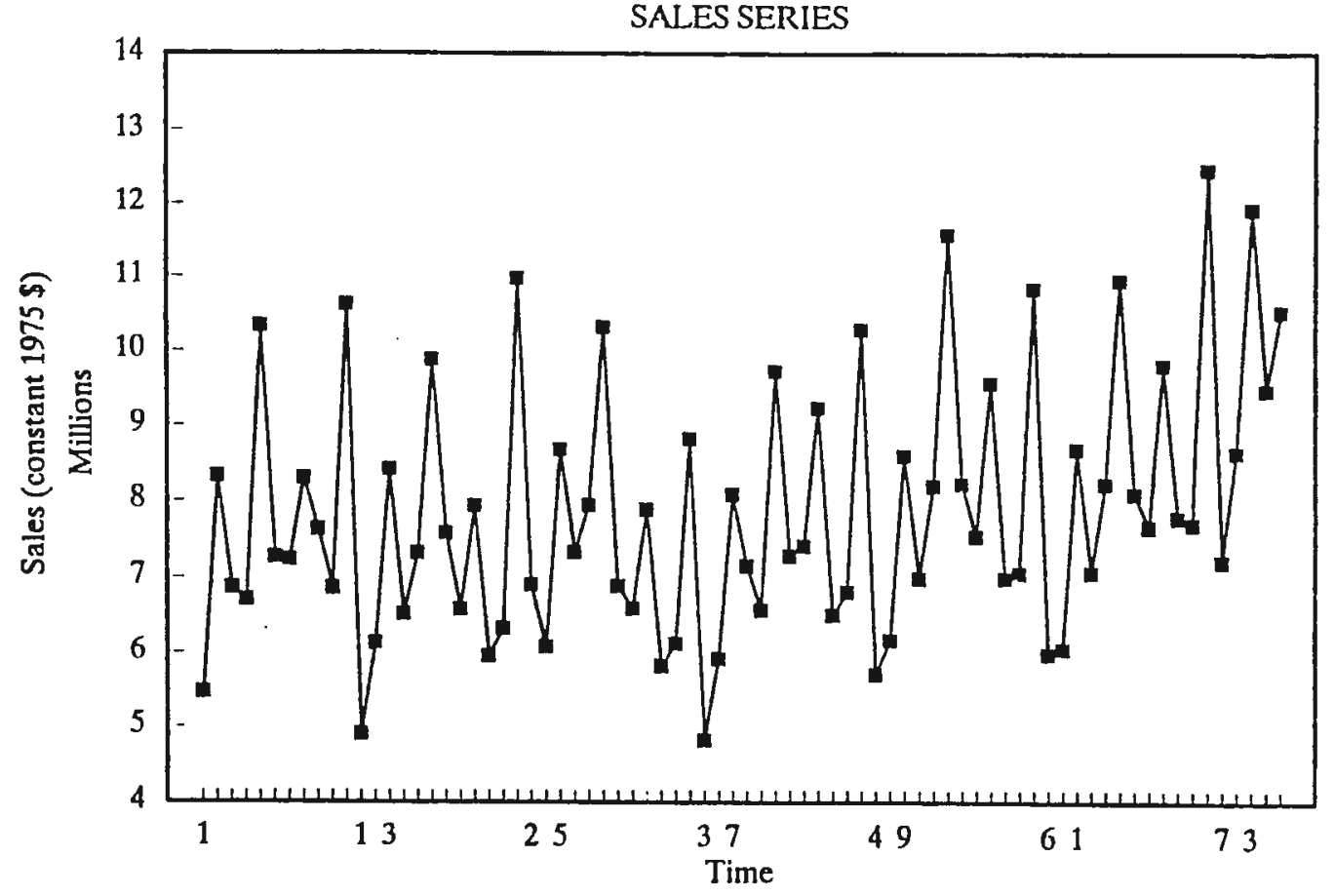

FIGURE 1B

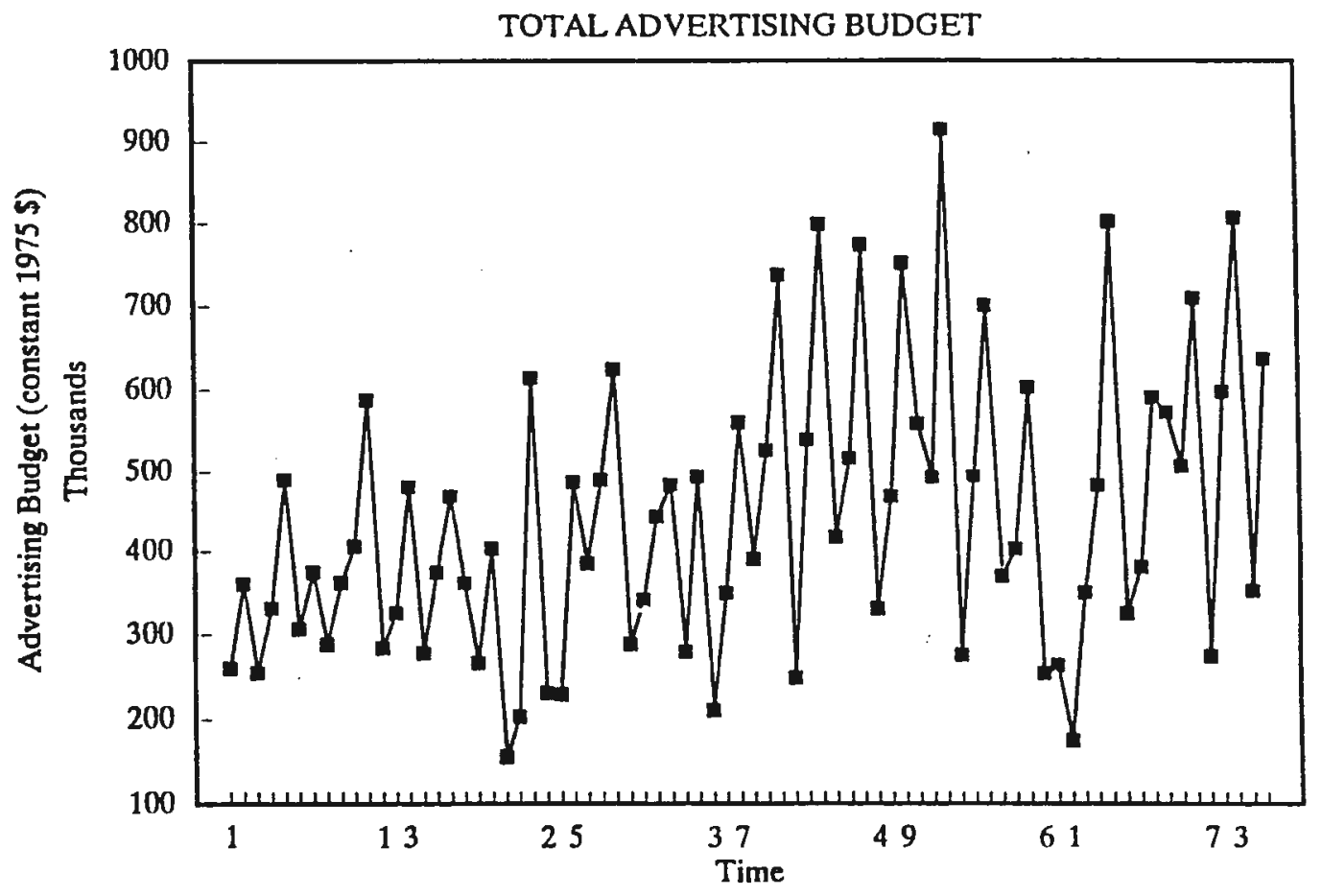


FIGURE 2

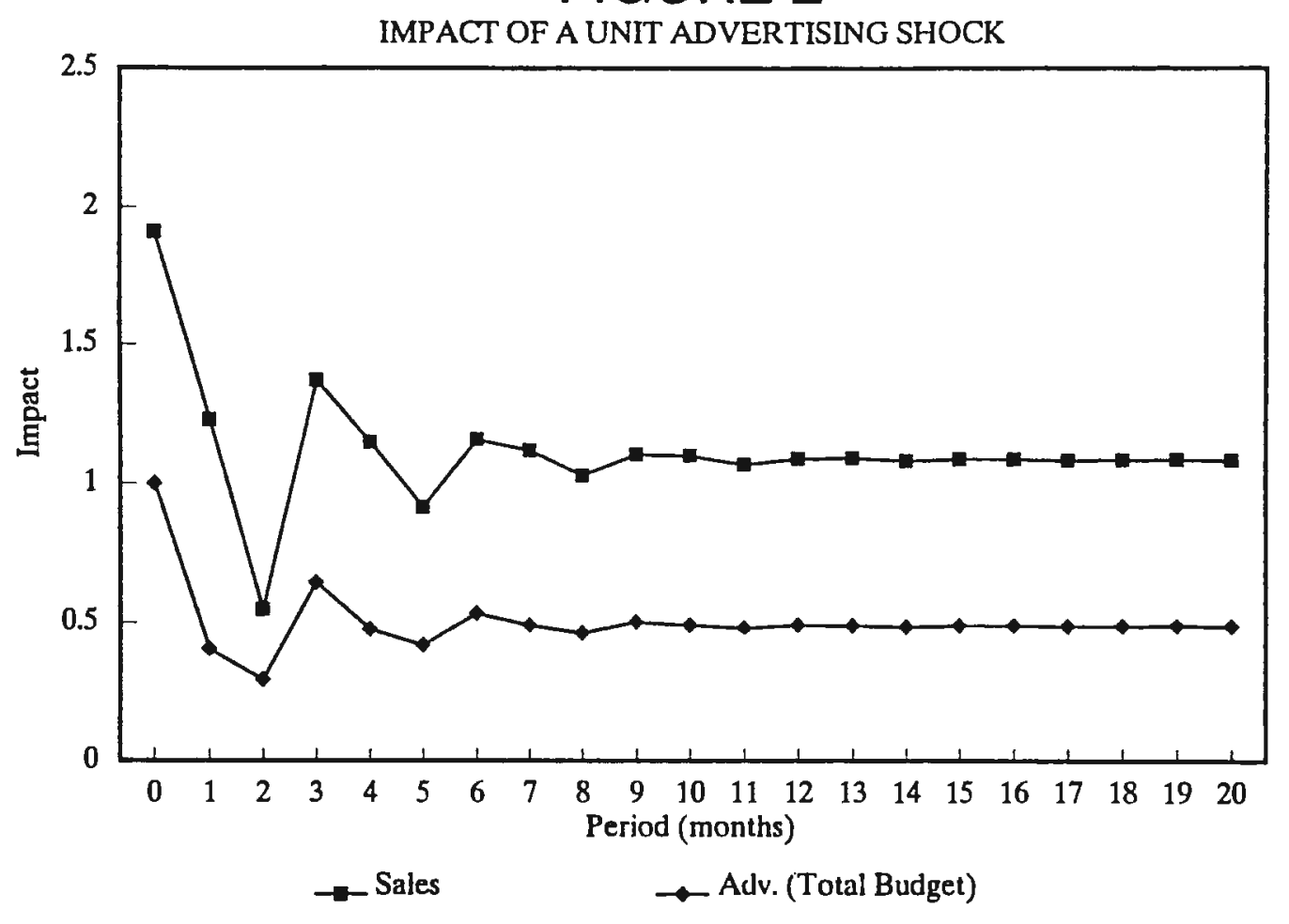


FIGURE $3 A$

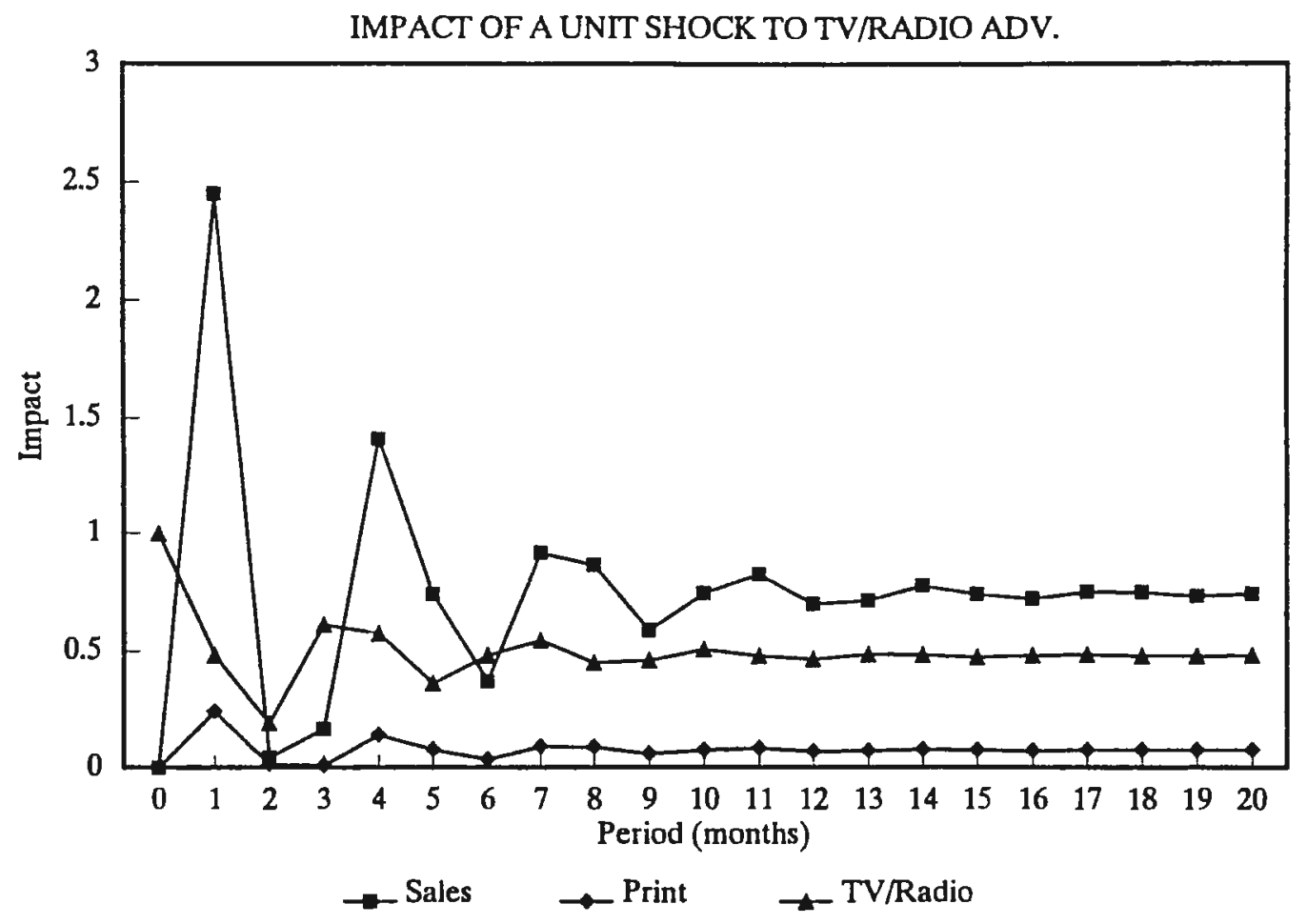

FIGURE 3B

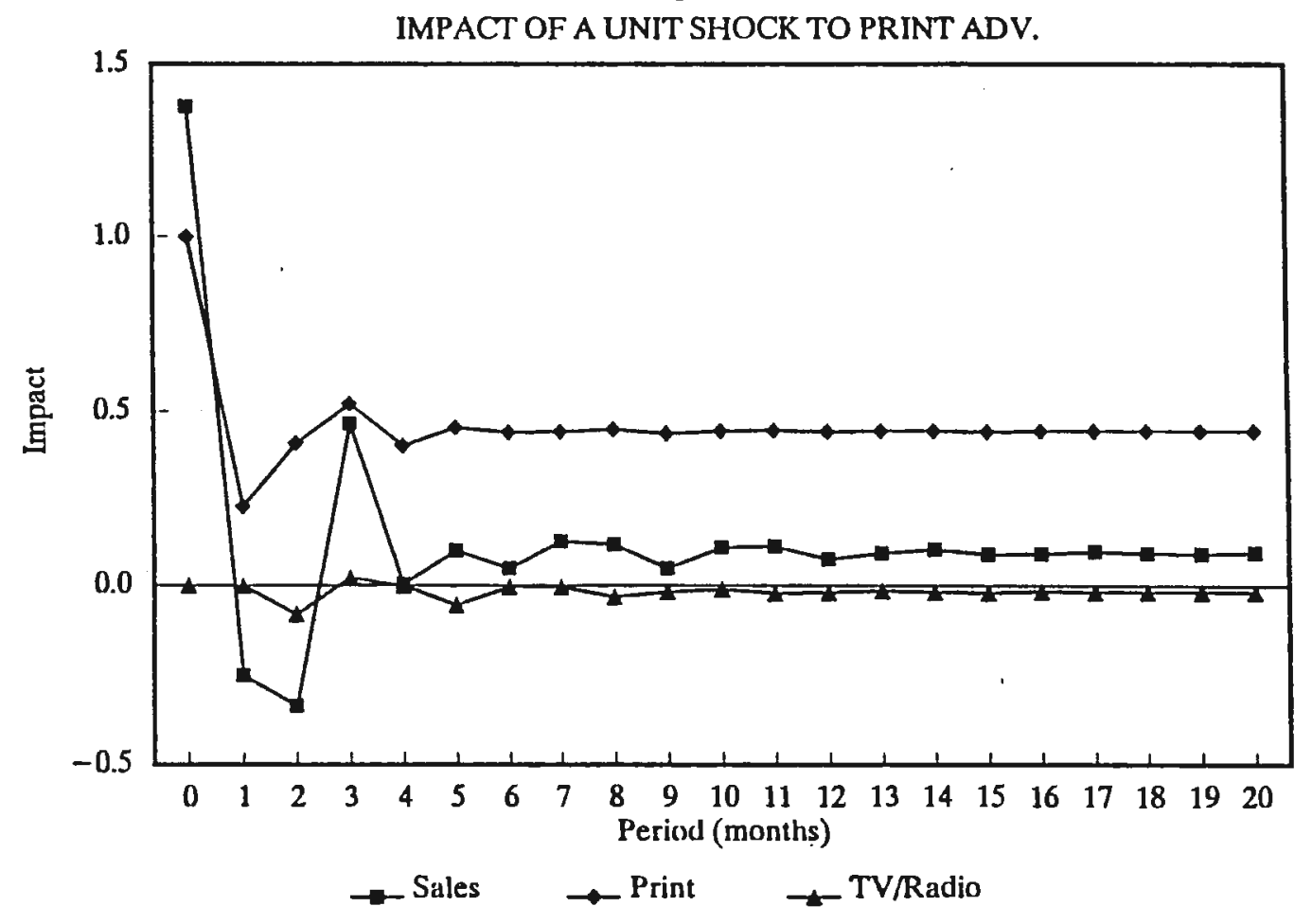

